\title{
Label-free imaging of macrophage phenotypes and phagocytic activity in the human dermis in vivo using two-photon excited FLIM
}

\author{
M. Kröger ${ }^{1}$, J. Scheffel ${ }^{1}$, E. A. Shirshin ${ }^{2}$, J. Schleusener ${ }^{1}$, M. C. Meinke ${ }^{1}$, J. Lademann ${ }^{1}$, \\ M. Maurer ${ }^{1}$, M. E. Darvin ${ }^{1 *}$ \\ ${ }^{1}$ Charité - Universitätsmedizin Berlin, corporate member of Freie Universität Berlin, Humboldt- \\ Universität zu Berlin, and Berlin Institute of Health, Department of Dermatology, Venerology and \\ Allergology, Charitéplatz 1, 10117 Berlin, Germany \\ ${ }^{2}$ Lomonosov Moscow State University, Faculty of Physics, 119991, Leninskie gory 1/2, Moscow, \\ Russia \\ * Corresponding author: Maxim E. Darvin \\ E-mail: maxim.darvin@charite.de
}

\begin{abstract}
Macrophages (MФs) are important immune effector cells that promote (M1 MФs) or inhibit (M2 MФs) inflammation and are involved in numerous physiological and pathogenic immune responses. Their precise role and relevance, however, is not fully understood because of the lack of non-invasive quantification methods. Here, we show that two-photon excited fluorescence lifetime imaging (TPE-FLIM), a label-free non-invasive method, can

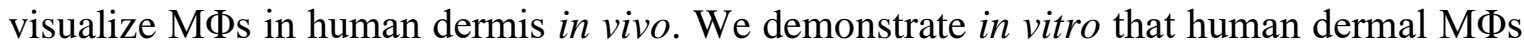
exhibit specific TPE-FLIM properties that distinguish them from the main components of the extracellular matrix and other dermal cells. We visualized MФs, their phenotypes and phagocytosis in the skin of healthy individuals in vivo using TPE-FLIM. Additionally, machine learning identified M1 and M2 MФs with a sensitivity of $0.88 \pm 0.04$ and $0.82 \pm 0.03$ and a specificity of $0.89 \pm 0.03$ and $0.90 \pm 0.03$, respectively. In clinical research, TPE-FLIM can advance the understanding of the role of MФs in health and disease.
\end{abstract}

\section{Introduction}

Macrophages (MФs) are important immune effector cells in organs and tissues that act as border junctions to environments such as the gut, the airways, and the skin (Elhelu, 1983). Skin MФs (Dong et al., 2016; Estandarte et al., 2016; Ryter, 1985) originate from circulating monocytes (Geissmann et al., 2010; Gordon and Taylor, 2005) via the same infiltration route into the dermis as monocyte-derived dendritic cells (Schmid and Harris, 2014) (Fig. 1a) and are mainly located in the papillary and reticular dermis in close proximity to blood vessels (Weber-Matthiesen and Sterry, 1990) (Figs. 1b-d). It has been known for more than 30 years that skin MФs are abundant and heterogeneous, based on their morphology, localization and staining properties (Weber-Matthiesen and Sterry, 1990). More recently, skin MФs have been classified based on their function, and they fall into two phenotypes referred to as inflammation-promoting M1 MФs (classically activated) and anti-inflammatory M2 MФs (alternatively activated) (Duque and Descoteaux, 2014) (Fig. 1a). M1 MФs are activated by viral and bacterial infection (Benoit et al., 2008; Ferrer et al., 2019; Malmgaard et al., 2004), interferon- $\gamma$, lipopolysaccharide (LPS), and tumor necrosis factor (TNF), which is known as the classical activation pathway (Li and Liu, 2018). M2 MФs are alternatively activated in response to IL-4, IL-13 and IL-33 (Furukawa et al., 2017; Sica and Mantovani, 2012). 
a

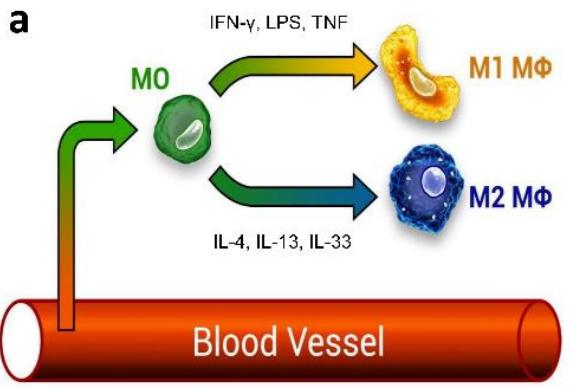

Epidermis

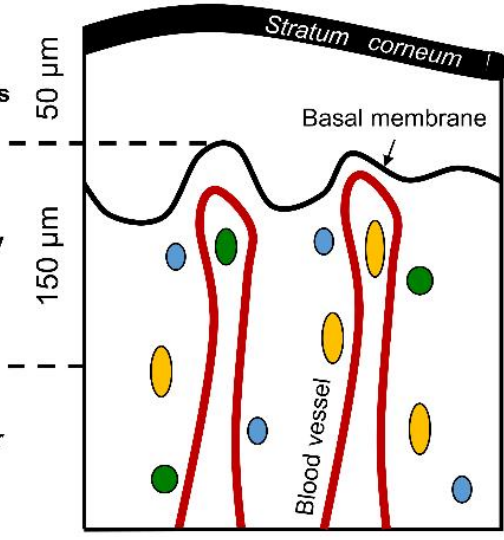

C
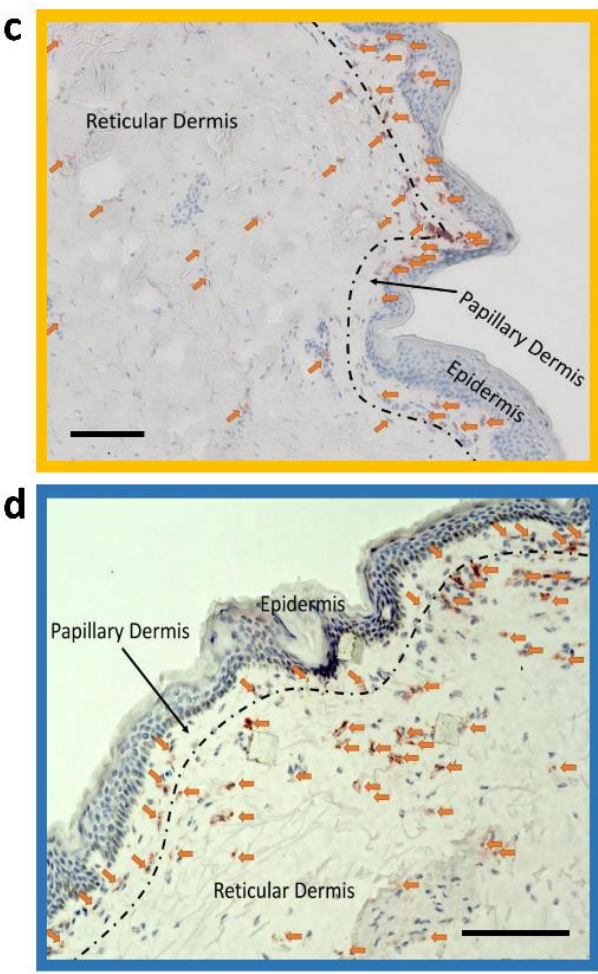

Figure 1. Dermal monocyte skin infiltration and CD68 stained M1 and CD163 stained M2 MФs distribution in excised human skin. Schematic illustration of monocyte (MO) (green) infiltration into tissues and macrophage (MФ)-polarization into M1 MФs (yellow) via IFN- $\gamma$, LPS and TNF and M2 MФs (blue) via IL-4, IL-13 and IL-33 (a). Schematic of skin with exemplary locations of monocytes (green), M1 MФs (yellow) and M2 MФs (blue) (b). Density of M1 MФs (marked with arrows) stained with CD68 (c) and M2 MФs (marked with arrows) stained with CD163 (d) in $10 \mu \mathrm{m}$ thick cryo-section. Scale bar $100 \mu \mathrm{m}$. Recently, this paradigm has been challenged, as many signals modulate $М \Phi$ functions, resulting in a continuum of states between the M1 and M2 phenotypes(Mendoza-Coronel and Ortega, 2017; Murray et al., 2014). However, for simplicity, the terms M1 and M2 MФs are used here.

Skin M1 MФs are held to contribute to dermal innate immunity and homeostasis. This is supported by reports that M1 MФs can phagocyte objects up to $20 \mu \mathrm{m}$ in size (Morhenn et al., 2002), promote skin inflammatory and immune responses (Remmerie and Scott, 2018; Theret et al., 2019; Yanez et al., 2017), and produce nitric oxide and other reactive oxygen species (ROS) (Forman and Torres, 2001; Rendra et al., 2019). Skin M2 MФs, on the other hand, are thought to promote dermal repair, healing and regeneration, for example by contributing to the formation of the extracellular matrix (Ploeger et al., 2013).

The precise role of skin MФs and their M1 and M2 phenotypes in health and disease remains to be elucidated. Efforts to do so include their quantification in healthy human skin and in lesional and non-lesional skin of patients with skin diseases. Currently, the most common approach is to obtain skin biopsies and to visualise MФs by immunohistochemistry. Skin biopsies, however, come with several important limitations, which include scarring, the risk of infection and bleeding, and artificial findings caused by the use of local anesthesia. Also, histopathological analyses of skin biopsies are not well suited for characterizing MФ functions such as phagocytosis and for long term monitoring of $М \Phi$ distribution in the skin. 
Fluorescence lifetime imaging (FLIM) employs $\mathrm{NAD}(\mathrm{P}) \mathrm{H}$ and fluorescence decay parameters of cellular compartments as specific indicators of cell types and phenotypes (Alfonso-García et al., 2016; Heaster et al., 2021). Combined with two-photon tomography, two-photon excited fluorescence lifetime imaging (TPE-FLIM) allows for label-free and non-invasive imaging of dermal cells. For instance, TPE-FLIM allows for in vitro imaging of mast cells, fibroblasts, neutrophils, and dendritic cells and in vivo imaging of mast cells in human skin (Kröger et al., 2020). Whether or not TPE-FLIM can be used to visualise human skin MФs, their M1 and M2 phenotypes, and their functions, is currently unknown. There are, however, several independent lines of evidence that support this approach: First, previous studies have shown that TPE-FLIM can distinguish MФs from other dermal cells and extracellular matrix (ECM), without prior labelling (Kröger et al., 2020). Second, the capillaries of the papillary dermis, which often are in a close proximity with MФs, show distinct TPE-FLIM signatures and are readily visualised (Shirshin et al., 2017). Third, M1 and M2 MФs come with unique cytokine patterns, and the TPE-FLIM signatures of these cytokines and patterns could help to tell the two phenotypes apart. Finally, TPE-FLIM can distinguish between functional states of dermal cells, e.g. resting and activated mast cells in vivo, МФs ex vivo (Kröger et al., 2020) and T-cell activation in vitro (Walsh et al., 2021) may, therefore, potentially allow for monitoring $М \Phi$ functions in vivo (Szulczewski et al., 2016). Taken together, the morphological features of skin MФs, their localization in the skin, and the expected differences in fluorescence decay parameters between MФ phenotypes as well as between other dermal cells, make TPE-FLIM a promising strategy for their detection (Yakimov et al., 2019).

Here, we first investigated human skin MФs, in vitro, for their TPE-FLIM properties and how these differ from those of the main components of the ECM and other dermal cells such as fibroblasts, mast cells, and dendritic cells. We then applied the identified MФ TPEFLIM signatures to investigate MФs and their phenotypes in human skin biopsies, combined with traditional immunohistochemistry-based visualization. Finally, we used TPE-FLIM in vivo in humans to study skin MФs, their phenotypes and functions, and we developed, tested, and characterised TPE-FLIM signature-based machine learning algorithms for the detection of skin MФs. 


\section{Results}

\section{In vitro monocyte-derived M1 and M2 MФs show distinct TPE-FLIM parameters}

The TPE-FLIM images of monocytes isolated from human peripheral blood mononuclear cells (PBMC) showed a round morphology (diameter of up to $10 \mu \mathrm{m}$ ) with a barely visible nucleus, homogeneously distributed cell content, and regular borders with no membrane extensions (Fig. S1). MФs differentiated from PBMC and polarised towards M1 MФs with interferon- $\gamma($ IFN- $\gamma ; n=21)$ and towards M2 MФs with interleukin-4 (IL-4; $n=27$ ) were similar in size, ranging from 10-12 $\mu \mathrm{m}$ (Fig. 2a, 2b and 2c). M1 and M2 MФs showed comparable overall TPE-AF intensities, but they differed significantly in several other features. M1 MФs also showed numerous bright spots (typical size is 2-3 $\mu \mathrm{m}$ ), likely vacuoles and mitochondria, had less visible borders, and exhibited higher TPE-AF intensity than M2 MФs. In contrast, M2 MФs were characterised by distinct borders with filopodia (Fig. 2b; Fig. S2), which were rarely seen in M1 MФs (Fig. 2a).

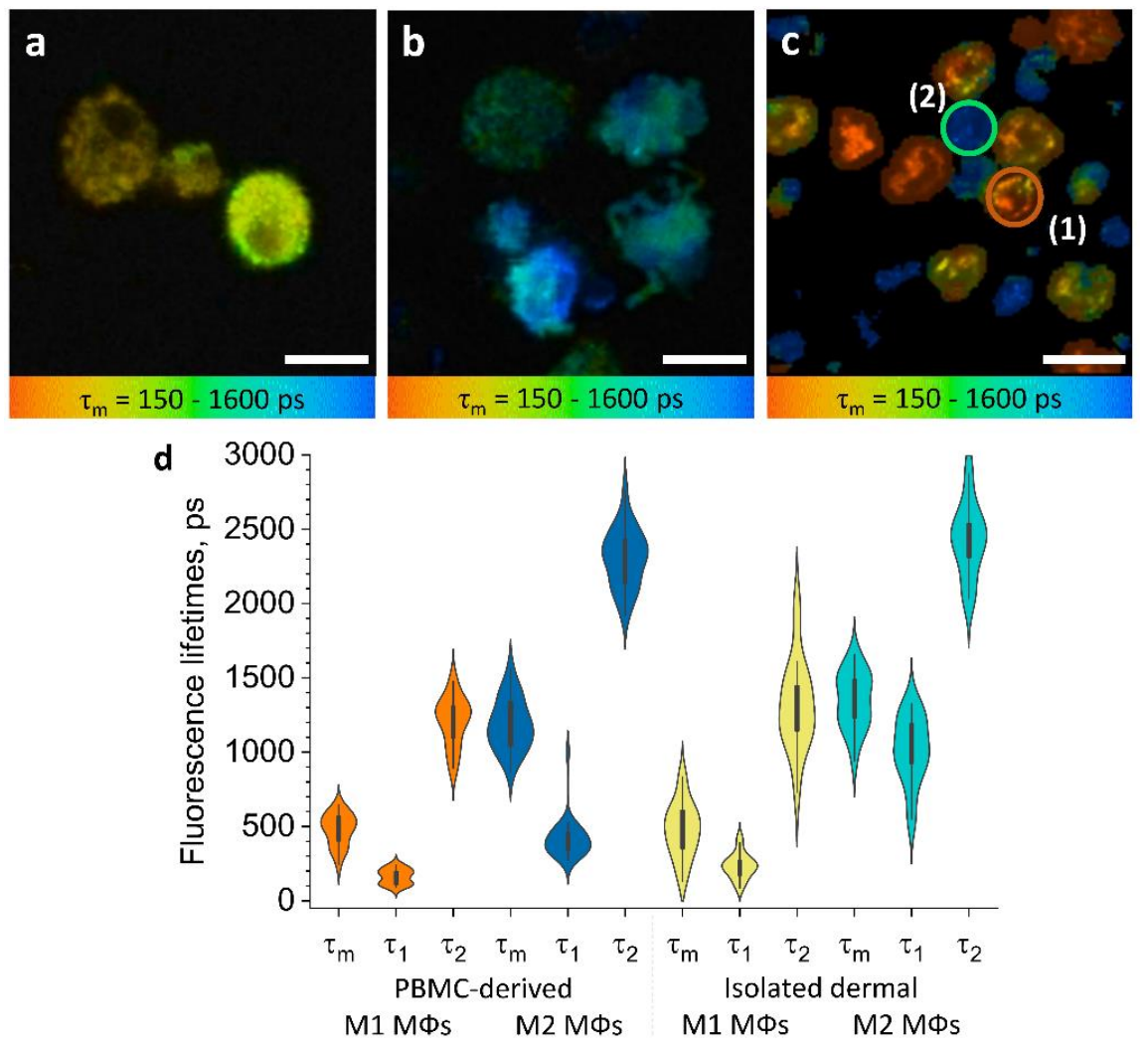

Figure 2. MФs polarised from PBMC and isolated dermal MФs show distinct TPEFLIM signatures. TPE-FLIM $\tau_{m}$ images (mean fluorescence lifetime $\tau_{m}$ in the $150-1600$ ps range) of monocyte-derived M1-polarised (IFN- $\gamma$ ) MФs (a), monocyte-derived M2-

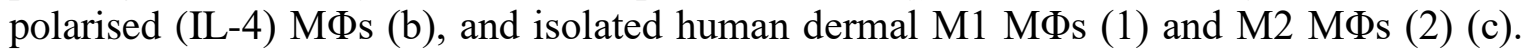
Scale bar: $10 \mu \mathrm{m}$. The distribution of TPE-FLIM parameters $\tau_{1}, \tau_{2}$ and $\tau_{m}$ for monocyte-

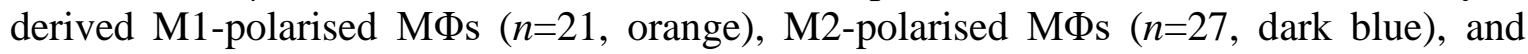

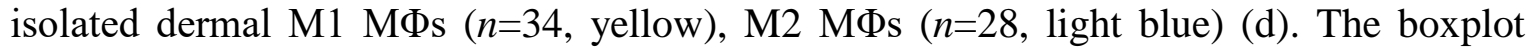
represents $25-75 \%$ of the values.

M1 and M2 MФs also differed in their TPE-FLIM parameters $\tau_{1}, \tau_{2}$, and $\tau_{m}$ (Fig. 2d). TPE-

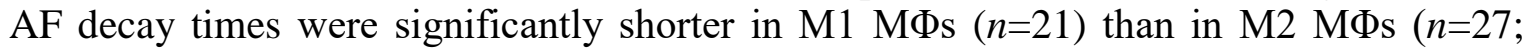
$p<0.05$ ), and both MФs differed significantly, in their TPE-FLIM parameters, from monocytes $(n=15 ; p<0.05$; Table 1$)$. 
IgG stimulation of IgG immune complex-sensitised M1 and M2 MФs resulted in the release of inflammatory mediators, but did not lead to significant changes or reveal additional differences in TPE-FLIM parameters 2 and 5 days after differentiation of PBMC into МФs (data not shown). Taken together, these findings indicate that monocyte-derived M1 МФs and M2 MФs can be identified and distinguished in vitro by their distinct TPE-FLIM signatures.

\section{MФs isolated from periocular skin show TPE-FLIM parameters that are similar to

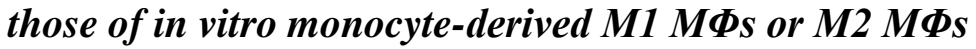

Human MФs isolated from periocular dermal tissue and analysed by immunohistochemistry were irregularly shaped, with poorly defined borders, $8-10 \mu \mathrm{m}$ in size, pericentral nuclei of 5-6 $\mu \mathrm{m}$ diameter with low fluorescence intensity, heterogeneously and irregularly distributed cellular content, and they exhibited a bright fluorescence multi-vacuolated cytoplasm with $\approx 1 \mu \mathrm{m}$ diameter small bright spots, presumably related to mitochondria and/or vacuoles (Fig. 2c). Based on their TPE-FLIM parameters, dermal МФs fell into two significantly different groups (Fig. 2d): group $1(n=34)$, with stronger TPE-AF intensity $(\approx 3,000 \pm 500$ photons $/ \mathrm{mW})$ and shorter lifetimes, and group $2(n=28)$, with a weaker TPEAF intensity $(\approx 800 \pm 200$ photons $/ \mathrm{mW})$ with longer lifetimes (Fig. 2c; Fig. S3). The profiles of dermal MФs in group 1 and 2 were similar to those of monocyte-derived M1 MФs and M2 MФs, respectively (Fig. 2d; Table 1). The biggest differences between group 1 / M1

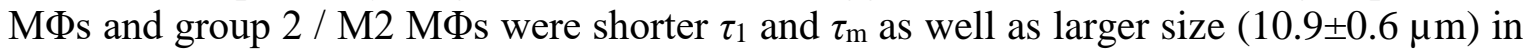
the former as compared to the latter $(9.8 \pm 1.2 \mu \mathrm{m} ; p<0.05$; Fig. $2 \mathrm{c}$ and $2 \mathrm{~d}$; Table 1$)$. This suggests that human skin MФs, based on their in vitro TPE-FLIM signatures, can be assigned to one of two phenotypes, where the first is similar to that of monocyte-derived M1 MФs and the second is similar to that of monocyte-derived M2 МФs.

Table 1. TPE-FLIM parameters for for investigated dermal and epidermal cells. TPEFLIM parameters $\tau_{1}, \tau_{2}, \tau_{\mathrm{m}}, a_{1} / a_{2}$ and TPE-AF intensity of monocyte-derived M1 and M2 $\mathrm{M \Phi s;} \mathrm{dermal} \mathrm{M1} \mathrm{and} \mathrm{M2} \mathrm{M \Phi s} \mathrm{isolated} \mathrm{from} \mathrm{the} \mathrm{skin} \mathrm{measured} \mathrm{in} \mathrm{vitro;} \mathrm{M1} \mathrm{(CD68)} \mathrm{and}$ M2 (CD163) MФs measured ex vivo in human skin cryo-sections; M1 and M2 MФs observed on the forearm of healthy volunteers in vivo; monocytes; resting and activated human skin mast cells; dendritic cells; fibroblasts and neutrophils in vitro.

\begin{tabular}{|c|c|c|c|c|c|c|c|}
\hline & & $\begin{array}{l}\text { Number } \\
\text { of cells }\end{array}$ & $\underset{\text { in } \mathbf{p s}}{\tau_{\mathbf{m}}}$ & $\begin{array}{c}\tau_{1} \\
\text { in } \mathrm{ps}\end{array}$ & $\begin{array}{c}\tau_{2} \\
\text { in ps }\end{array}$ & $a_{1} / a_{2}$ & $\begin{array}{c}\text { TPE-AF } \\
\text { intensity, } \\
\text { photons } / \mathbf{m W}\end{array}$ \\
\hline $\begin{array}{c}\text { in } \\
\text { vitro }\end{array}$ & $\begin{array}{l}\text { Monocyte- } \\
\text { derived M1- } \\
\text { polarised MФs }\end{array}$ & 21 & $479 \pm 106$ & $163 \pm 50$ & $1,209 \pm 161$ & $2.4 \pm 0.6$ & $600 \pm 100$ \\
\hline $\begin{array}{c}\text { in } \\
\text { vitro }\end{array}$ & $\begin{array}{c}\text { Monocyte- } \\
\text { derived M2- } \\
\text { polarised MФs }\end{array}$ & 27 & $1,185 \pm 170$ & $417 \pm 134$ & $2,305 \pm 194$ & $2.3 \pm 0.5$ & $500 \pm 100$ \\
\hline $\begin{array}{c}\text { in } \\
\text { vitro }\end{array}$ & $\begin{array}{l}\text { M1 isolated } \\
\text { dermal MФs }\end{array}$ & 34 & $461 \pm 175$ & $225 \pm 84$ & $1,289 \pm 278$ & $4.8 \pm 3.4$ & $3,000 \pm 500$ \\
\hline $\begin{array}{c}\text { in } \\
\text { vitro }\end{array}$ & $\begin{array}{l}\text { M2 isolated } \\
\text { dermal MФs }\end{array}$ & 28 & $1,281 \pm 155$ & $807 \pm 250$ & $2,352 \pm 229$ & $2.2 \pm 1.1$ & $800 \pm 200$ \\
\hline
\end{tabular}




\begin{tabular}{|c|c|c|c|c|c|c|c|}
\hline $\begin{array}{c}e x \\
\text { vivo }\end{array}$ & $\begin{array}{c}\text { M1 MФs } \\
\text { (CD68) }\end{array}$ & 8 & $458 \pm 50$ & $190 \pm 38$ & $1,504 \pm 133$ & $4.1 \pm 0.7$ & $3,000 \pm 500$ \\
\hline $\begin{array}{c}\text { ex } \\
\text { vivo }\end{array}$ & $\begin{array}{l}\text { M2 MФs } \\
\text { (CD163) }\end{array}$ & 12 & $1,369 \pm 201$ & $498 \pm 129$ & $2,267 \pm 155$ & $1.1 \pm 0.4$ & $700 \pm 300$ \\
\hline $\begin{array}{c}\text { in } \\
\text { vivo }\end{array}$ & M1 MФs & 35 & $477 \pm 105$ & $196 \pm 40$ & $1,698 \pm 172$ & $5.0 \pm 2.8$ & $686 \pm 165$ \\
\hline $\begin{array}{c}\text { in } \\
\text { vivo }\end{array}$ & $\begin{array}{c}\text { Phagocytosing } \\
\text { M1 МФs }\end{array}$ & 2 & $195 \pm 44$ & $105 \pm 10$ & $1,272 \pm 89$ & $14.7 \pm 4.5$ & $1,100 \pm 150$ \\
\hline $\begin{array}{c}\text { in } \\
\text { vivo }\end{array}$ & M2 MФs & 25 & $1,407 \pm 60$ & $442 \pm 54$ & $2,458 \pm 90$ & $1.2 \pm 0.2$ & $360 \pm 155$ \\
\hline $\begin{array}{c}\text { in } \\
\text { vitro }\end{array}$ & $\begin{array}{l}\text { PBMC-derived } \\
\text { monocytes }\end{array}$ & 15 & $989 \pm 111$ & $491 \pm 130$ & $2,025 \pm 301$ & $1.8 \pm 0.5$ & $700 \pm 130$ \\
\hline $\begin{array}{c}\text { in } \\
\text { vitro }\end{array}$ & $\begin{array}{c}\text { Resting } \\
\text { mast cells }\end{array}$ & 43 & $1,248 \pm 287$ & $533 \pm 266$ & $2,289 \pm 317$ & $1.5 \pm 0.5$ & $1,300 \pm 400$ \\
\hline $\begin{array}{c}\text { in } \\
\text { vitro }\end{array}$ & $\begin{array}{l}\text { Activated } \\
\text { mast cells }\end{array}$ & 13 & $862 \pm 268$ & $288 \pm 130$ & $1,920 \pm 287$ & $2.5 \pm 2.0$ & $900 \pm 200$ \\
\hline $\begin{array}{c}\text { in } \\
\text { vitro }\end{array}$ & Dendritic cells & 14 & $1,265 \pm 180$ & $434 \pm 188$ & $2,578 \pm 328$ & $1.6 \pm 0.2$ & $538 \pm 258$ \\
\hline $\begin{array}{c}\text { in } \\
\text { vitro }\end{array}$ & Fibroblasts & 6 & $921 \pm 81$ & $429 \pm 51$ & $1,983 \pm 137$ & $0.5 \pm 0.1$ & $469 \pm 137$ \\
\hline $\begin{array}{c}\text { in } \\
\text { vitro }\end{array}$ & Neutrophils & 21 & $1,074 \pm 109$ & $714 \pm 250$ & $1,795 \pm 600$ & $1.5 \pm 0.5$ & $500 \pm 115$ \\
\hline
\end{tabular}

\section{TPE-FLIM can distinguish between MФs and other cells}

To prove that the recorded TPE-FLIM signatures are unique for M1- and M2-polarized MФs (Fig. 2), we performed TPE-FLIM measurements of other dermal cells in vitro, such as mast cells, dendritic cells, fibroblasts, monocytes and neutrophils. Their TPE-FLIM parameters, summarised in Table 1, are markedly different from those of the established signatures of M1- and M2-polarized MФs. Thus, in addition to size, morphology, and internal vacuole structure, M1- and M2-polarized MФs can be distinguished, from each other and other cells, by distinct TPE-FLIM parameters, a prerequisite for the visualization of skin MФs ex vivo and in vivo. Table 1 is an extension of the results shown in Kröger et al.(Kröger et al., 2020) 


\section{Immunohistochemistry confirms TPE-FLIM detection of M1 and M2 MФs in human skin ex vivo}

To test if the TPE-FLIM signatures established in vitro identify M1- and M2-polarized MФs in human skin, we sequentially analyzed dermal biopsies by TPE-FLIM and conventional immunohistochemistry. The application of in vitro MФ signatures to TPE-FLIM analyses of 13 human skin biopsy cryo-sections identified two distinct cell populations: The first showed a short mean fluorescence lifetime $\tau_{\mathrm{m}}$ and high TPE-AF intensity, a feature of M1 MФs (Table 1, Fig. 2d, Fig. 3a); the second population showed longer $\tau_{\mathrm{m}}$ and significantly lower TPE-AF intensity, typical for M2 MФs (Table 1, Fig. 2d, Fig. 3c). CD68-staining for M1 MФs and CD163-staining for M2 MФs confirmed that short $\tau_{\mathrm{m}}$ cells with high TPE-AF intensity were, indeed, M1 MФs (Fig. 3b) and that cells with longer $\tau_{1}, \tau_{2}, \tau_{\mathrm{m}}$ with low TPEAF intensity were, indeed, M2 MФs (Fig. 3d, Fig. S4, Table 1).
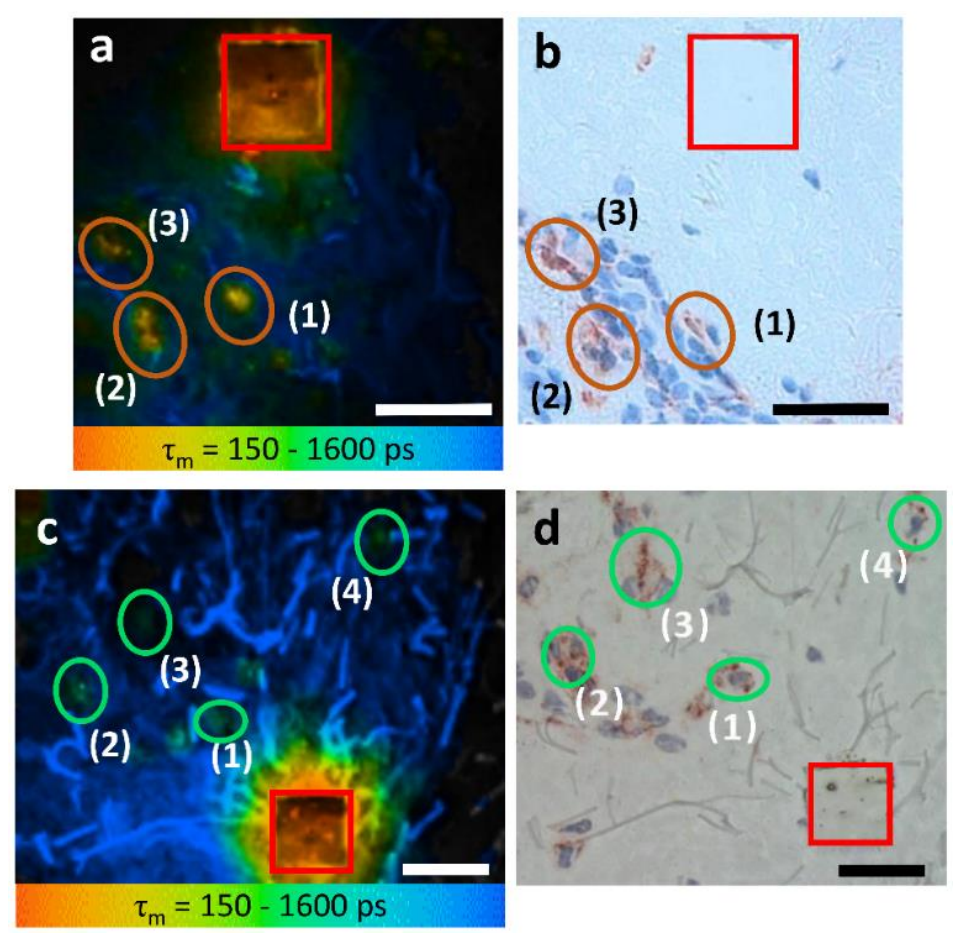

Figure 3. M1 and M2 MФs ex vivo verified using TPE-FLIM parameters and immunohistochemistry-based bright field microscopy. Side by side comparison of TPEFLIM $\tau_{\mathrm{m}}$ image (mean fluorescence lifetime $\tau_{\mathrm{m}}$ in the $150-1,600 \mathrm{ps}$ range), which were measured label-free and then stained with CD68-antibody for M1 MФs (a), and CD163antibody for M2 MФs (c) and corresponding bright field microscopic images (b) and (d). The excitation wavelength is $760 \mathrm{~nm}$ and laser power is $4 \mathrm{~mW}$ (a) and $2 \mathrm{~mW}$ (c). The M1 and M2 MФs are marked with ellipses in $(a, b)$ and in $(c, d)$, respectively. The laser-burned labels $(28 \mu \mathrm{m} \times 28 \mu \mathrm{m})$ are marked in red. The suspected $(\mathrm{a}, \mathrm{c})$ and staining-proved $(\mathrm{b}, \mathrm{d})$ MФs are marked with number (1, 2, 3 and 4). More M2 MФs are observed in (d) compared to (c) due to the staining and visualization of the entire biopsy volume in (d) and limited imaging plane of the two-photon tomograph $(1.2-2.0 \mu \mathrm{m})$ in (c). Images have been rotated and zoomed to match their orientation and size. Scale bar: $30 \mu \mathrm{m}$.

CD68-positive dermal M1 MФs showed a heterogeneous appearance, ranging from flat and spindle shaped vessel lining to big intravascular with irregular borders and an irregular nucleus (Fig. 3b). The TPE-FLIM image of CD163-positive M2 MФs show round to 
elliptical shaped cells with a significantly lower TPE-AF intensity (Fig. 3d). Of nine cells with a TPE-FLIM M1 MФ signature, eight cells stained positive for CD68, and all CD68positive cells had a TPE-FLIM M1 MФ signature. As for M2 MФs, all cells with a TPEFLIM M2 MФ signature (12 of 14) were CD163-positive, and all CD163-positive cells had a TPE-FLIM M2 M $\Phi$ signature.

\section{TPE-FLIM visualises human skin M1 and M2 MФs in vivo}

Next, we used TPE-FLIM to assess the skin of 25 healthy individuals in vivo, and we identified and further characterised 35 and $25 \mathrm{M \Phi s}$ with a M1 and M2 TPE-FLIM signature, respectively. In vivo, similar to biopsy sections, M1 and M2 MФs were located in the papillary and reticular dermis at $>80 \mu \mathrm{m}$ depth (Fig. 4) and showed a density of $>100$ $\mathrm{M} \Phi \mathrm{s} / \mathrm{mm}^{2}$ (Figs. 1c, 1d). M1 МФs fell into three distinct groups and were either flat and spindle shaped (Fig. 4a), slightly dendritic (Fig. 4b) or large and intervascular (Fig. 4c). M2 MФs, in human skin in vivo, were round and moderately dendritic (Fig. 4d), and they had a higher TPE-AF intensity in vivo compared to the ECM, as previously reported in vitro(Malissen et al., 2014; Njoroge et al., 2001).

The TPE-FLIM parameters of in vivo M1 MФs were in agreement with those of in vitro monocyte-derived and dermal M1 MФs and ex vivo M1 MФs (Fig. 4e, Table 1). M2 MФs in vivo have longer $\tau_{\mathrm{m}}$ fluorescence lifetimes compared to in vitro and ex vivo experiments. Yet, the $\tau_{1}$ and $\tau_{2}$ were in agreement with in vitro PBMC-derived monocytes, and the size and morphological parameters were in line with what is expected in M2 MФs. The 2D segmentation in Fig. S5 shows the distinction of M1 and M2 MФs presented in Figs. 4a-d, and the phasor plot in Fig. 4f shows that M1 and M2 MФs could be distinguished from each other and from other dermal cells and ECM.
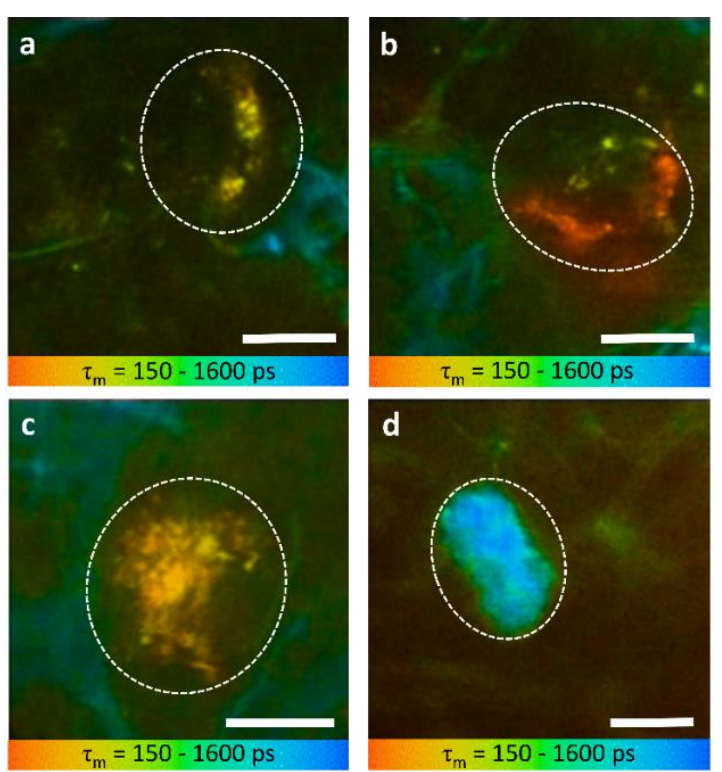

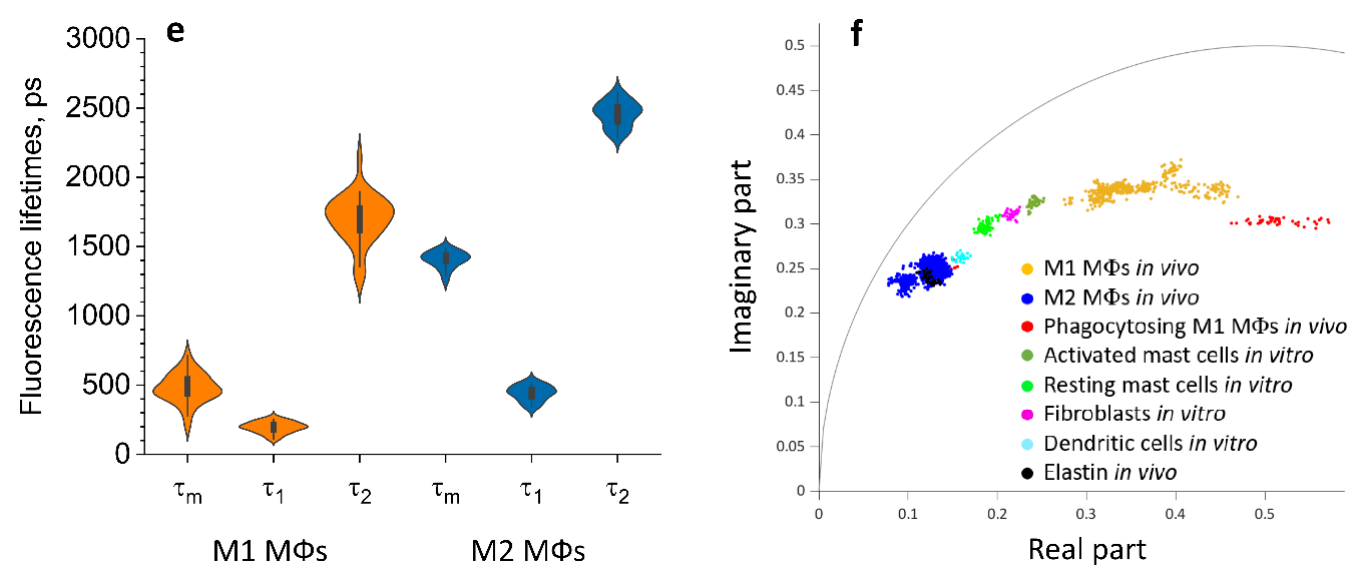

Figure 4. MФs are visualised and categorised by TPE-FLIM signatures in vivo. TPEFLIM in vivo images of potential perivascular flat spindle shaped M1 MФ (a), of suspected slightly dendritic M1 MФ in the depth $90 \mu \mathrm{m}$ (b) large intervascular M1 MФ with membrane extensions (c) and in vivo dermal cells resembling M2 M $\Phi$ were observed with a significantly longer mean fluorescence lifetime $\tau_{\mathrm{m}}$ compared to M1 MФs and less pronounced TPE-AF intensity (d), showing mean fluorescence lifetime $\tau_{m}$ in colour gradient from 150 to 1,600 ps. Scale bar: $10 \mu \mathrm{m}$. The histogram shows the distribution of TPE-FLIM parameters for in vivo MФs (e). The boxplot represents $25-75 \%$ of the values. The phasor plot has a threshold at 0.9 of the maximum intensity and shows a summary of $12 \mathrm{M} 1,2$

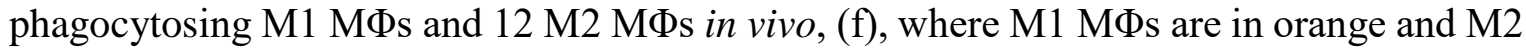

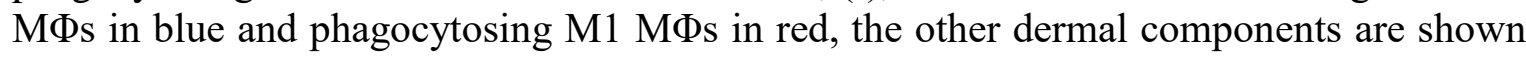
from in vitro measurements. The in vivo images $(\mathrm{a}-\mathrm{d})$ were recorded at $760 \mathrm{~nm}$ excitation wavelength, $50 \mathrm{~mW}$ laser power and $6.8 \mathrm{~s}$ acquisition time, in the depth of 80-100 $\mu \mathrm{m}$ on the volar forearm skin area of 25 healthy human subjects.

\section{TPE-FLIM can distinguish resting from phagocytosing human skin M1 MФs in vivo}

Phagocytosing skin M1 MФs are characterized by an increase in cell size(May and Machesky, 2001), enhanced vacuolization(Cheng et al., 2019) and a shift of TPE-FLIM parameters towards shorter fluorescence lifetime values(Yakimov et al., 2019), different from those of resting M1 and M2 MФs. A dermal cell matching these criteria is visualized in vivo using TPE-FLIM and presented in Fig. 5. This cell is located in the reticular dermis, has an enlarged size $(\approx 25 \mu \mathrm{m})$ and an oval shape, similar to the resting M1 M $\Phi$ in Fig. $4 \mathrm{c}$, pronounced vacuole structure and short TPE-FLIM lifetime specific for phagocytosing M1 МФ. Of 37 dermal M1 MФs analysed, 2 showed phagocytosis, and both were located in the reticular dermis below $100 \mu \mathrm{m}$ of depth. 

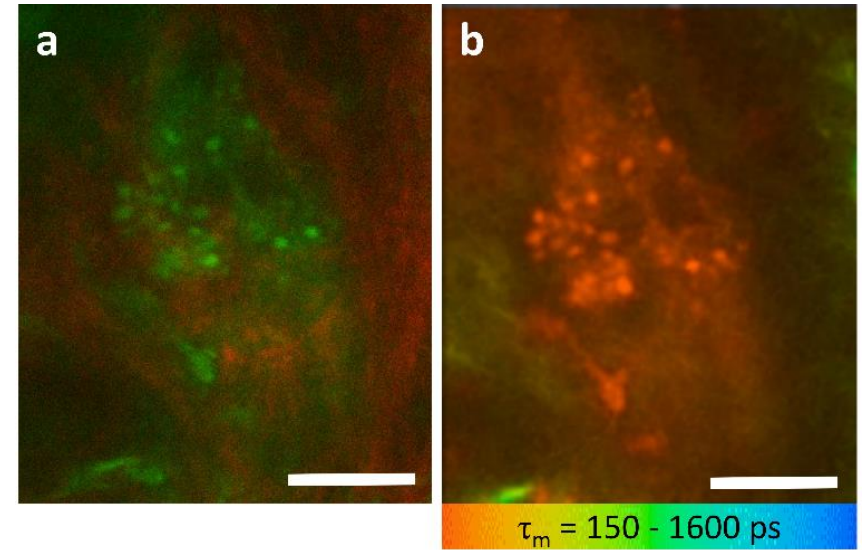

\section{Discussion}

This is the first in vivo study to show that human skin MФs can be distinguished from other dermal cells and quantified through visualization with label-free, completely non-invasive TPE-FLIM. This risk-free approach also allows for the identification of MФ phenotypes, i.e. M1 and M2 MФs, and for the characterization of their functional stage, i.e. resting vs phagocytosing M1 MФs. Finally, TPE-FLIM can be used to implement sensitive and specific machine learning algorithms for $М \Phi$ detection in the skin.

Our initial work with CD-14 positive monocytes isolated from PBMC and then differentiated and polarised towards M1 (IFN- $\gamma$ ) and M2 (IL-4) MФs was needed to establish their TPE-FLIM parameters. In fact, it showed that MФs are fluorescence-active, and, more importantly, that their TPE-FLIM parameters are among the best differentiators 
of M1 $\left(\tau_{m}=479 \pm 106\right)$ and M2 $\left(\tau_{m}=1,185 \pm 170\right)$ MФs. M1 MФs are associated with a slightly higher TPE-AF intensity (Table 1), which is a prominent indicator for the metabolic stress of the cell on account of a shift in lifetimes by changing amounts of free and bound $\mathrm{NAD}(\mathrm{P}) \mathrm{H}$ (Al-Shabany et al., 2016) and generation of ROS in mitochondria, phagosomal vacuoles and the cell membrane (Datta et al., 2015). Additionally to $\mathrm{NAD}(\mathrm{P}) \mathrm{H}$, autofluorescence of lipids and other cell compartments was recorded. TPE-AF intensity is a parameter with limitation due to the nonlinear imaging technique. There is no linear correlation between excitation and emission intensity, also it is reduced due to scattering and absorption in the skin. The longer fluorescence lifetime $\tau_{2}$ in M2 MФs is best explained by oxidative phosphorylation and the emergence of fluorophores caused by fatty acid oxidation(Viola et al., 2019). NAD(P)H fluorescence is ubiquitously present in cells and exhibits the continuum of lifetimes in the 360-3,400 ps range. Free NAD(P)H has a short lifetime of $360 \mathrm{ps}$. For bound $\mathrm{NAD}(\mathrm{P}) \mathrm{H}$, longer lifetimes up to 2-4 ns have been reported(Alfonso-García et al., 2016). A higher ratio of bound to free $\mathrm{NAD}(\mathrm{P}) \mathrm{H}$ is associated with M2 MФs resulting in longer TPE-FLIM parameters, while a lower ratio of bound to free $\mathrm{NAD}(\mathrm{P}) \mathrm{H}$ is associated with $\mathrm{M} 1 \mathrm{M} \Phi \mathrm{s}$ resulting in faster TPE-AF decay(Blacker et al., 2014). Thus, a strong indicator for the M $\Phi$ polarization is the TPEFLIM parameters of monocytes in between cohorts of MФs.

Translation of our in vitro findings to MФs isolated from human skin confirmed that the latter share the TPE-FLIM signatures of the former, with shorter $\tau_{m}$ in dermal M1 MФs and longer $\tau_{m}$ in dermal M2 MФs. The classification into M1 and M2 MФs in vitro based on their distinct TPE-FLIM parameters was supported by their differences in size, morphology and internal vacuole structure. That the $\tau_{1}$ lifetime of dermal M2 MФs is longer than that of monocyte-derived M2 MФs is most likely due to the use of different polarization agents.

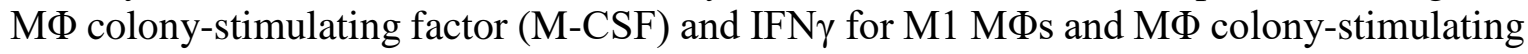
factor (M-CSF) and IL-4 for M2 MФs were used in PBMC-derived MФs and microenvironment effects like inflammatory signals, UV exposure (Kang et al., 1994) and immune responses (Theret et al., 2019) influencing MФ functions, result in divergent fluorescence lifetimes (Zhang et al., 2014) (Table 1, Fig. 2d). The most important outcome of our work with dermal MФs was the establishment of their phenotype-specific TPE-FLIM signatures, a prerequisite for our subsequent in vivo studies and for comparing skin MФs and other dermal cells.

In fact, the use of the TPE-FLIM signatures of M1 and M2 MФs clearly allowed to distinguish them from mast cells, dendritic cells, fibroblasts and neutrophils (Table 1, Fig. 4f) (Kröger et al., 2020). We controlled for this by independent markers. For example, MФs exhibited a higher fluorescence intensity compared to other dermal cells. In addition, they were larger than dermal mast cells, and their morphology was clearly different from that of neutrophils and fibroblasts. Vacuoles, a defining feature of MФs, were linked to MФ TPEFLIM parameters, whereas granules, which identify mast cells, were not. In short, dermal MФs, in their TPE-FLIM profiles, do not superimpose with other dermal cells or structures. The only exception, a partial overlap between M2 MФs and elastin, is not relevant for the visualization of the former, as they are readily distinguished from the latter based on their morphology.

To confirm that ex vivo TPE-FLIM overlap with TPE-FLIM signatures of M1 and M2 MФs in vitro, we sequentially analyzed cells in skin biopsy cryosections with TPE-FLIM and conventional immunohistochemistry. Indeed, both approaches identified and distinguished matching $M \Phi$ populations, i.e. M1 and M2 M $\Phi$ s, with strong fluorescence intensity and spindle shape appearance of M1 MФs and lower fluorescence intensity and longer fluorescence decay in M2 MФs (Fig. 3). Interestingly, M2 MФs are often found in an area 
of higher density of unknown dermal cells, presumably fibroblasts, compared to M1 МФs. It is suspected that $\mathrm{M} 2 \mathrm{M} \Phi \mathrm{s}$ in conjunction with collagen synthesizing fibroblasts are acting towards and aiding in dermal repair and regeneration. However, this approach also revealed some challenges that come with MФ visualization by TPE-FLIM. For example, it was more difficult to visualise M2 MФs than M1 MФs in biopsies due to the high fluorescence intensity of elastin in dried tissue and other ECM components and a decreased signal-tonoise ratio. In Fig. 3d more CD163 positive M2 MФs are visible compared to the corresponding TPE-FLIM image in Fig. 3c, which is due to previously mentioned challenges and the limited imaging plane of the two-photon tomograph $(1.2-2.0 \mu \mathrm{m})$ compared to significantly thicker biopsy section $(10 \mu \mathrm{m})$, which was stained in an entire depth and visualized by bright field microscopy. Importantly, immunohistochemistry confirmed our M $\Phi$ phenotype-specific TPE-FLIM signatures, and, in addition, confirmed that they distinguish $М \Phi$ s from other dermal cells. Skin mast cells, for example, stained for tryptase, showed a distinct TPE-FLIM signature, confirming our recently reported findings on dermal mast cells in vivo (Kröger et al., 2020), and distinguished them from M1 and M2 MФs (Fig. S8).

When we turned to the visualization of skin MФs in vivo, we had to first develop a search strategy. Important considerations included the preferred localization of МФs in the papillary and reticular dermis, the orientation of the focal plane parallel to the skin surface, and the need for maximal cellular cross-section visualization, which requires a highresolution adjustment in depth to reconstruct an entire cell structure. The application of this search algorithm successfully visualised M1 and M2 MФs in human skin in vivo. The in vivo TPE-FLIM parameters of M1 MФs were in agreement with those observed in vitro and ex vivo. М2 МФs in vivo were characterised by longer mean fluorescence lifetime $\tau_{\mathrm{m}}$ compared to in vitro and ex vivo (Table 1), which can be explained by the influence of environment (Koo and Garg, 2019; Njoroge et al., 2001). МФs measured in vivo differ from cells measured in vitro by their simplified microenvironment (Mosser and Edwards, 2008) with missing growth factors and cytokines (Melton et al., 2015) and an elevated level of nutrients, which leads to different polarization of $M \Phi s$ and different contributions of fluorescence lifetimes. Membrane extensions were harder to detect in vivo due to the obscuring effect of the surrounding ECM. We also observed that TPE-FLIM parameters in the same MФs can vary depending on their cellular substructures, e.g. the nucleus, vacuoles, cytoplasm, or membrane (Figs. 4a-d). The phasor plot shows the relative position of the categories of MФs and other cells. Furthermore, it shows the contributions of long and short fluorescence lifetimes and their discrepancies (Table 1) are due to the computational method and the harmonics at the repetition frequency of $80 \mathrm{MHz}$. Further investigations are needed to clarify how the location, morphology, and function of M1 and M2 MФs influence their TPE-FLIM parameters and TPE-AF intensity in vivo. Such studies should also investigate the reasons for the differences in TPE-FLIM parameters between M1 and M2 MФs, which may include differences in their metabolic pathways. M1 MФs, for example, rely on NADH oxidase and production of ROS, which is linked to short fluorescence lifetimes of under 250 ps and mitochondrial fission. M2 MФs, on the other hand, rely on oxidative phosphorylation and fatty acid oxidation, together with mitochondrial fusion (Ramond et al., 2019; Swindle et al., 2002; Xu et al., 2016).

The ability to visualise M1 and M2 MФs by TPE-FLIM in vivo also makes it possible to explore how and why MФs' morphology, location and functions are linked. When activated, the cytoskeletal structure and cellular appearance of $M \Phi$ s change, and this may also affect their TPE-FLIM parameters. M1 MФs are elongated, with a dense actin network along the cortex. M2 MФs are more spherical with more randomly distributed actin (Porcheray et al., 2005; Vogel et al., 2014; Zhang et al., 2014) (Figs. 4b and 4d). Actin reorganization in M1 
and M2 MФ polarization and activation lead to bigger filament bundles of the actin cytoskeleton, which reduces cell plasticity (Colin-York et al., 2019; Pergola et al., 2017). As reported by Daphne and coworkers (Vogel et al., 2014), MФ migration in the skin depends on their polarization. M1 MФs, due to changes in actin cytoskeleton, migrate less far than M2 MФs. Our TPE-FLIM findings confirm this, as we detected M1 MФs via their high fluorescence and short autofluorescence lifetimes primarily in close proximity to blood capillaries. The irregular appearance of M1 MФ detected by TPE-FLIM is likely a consequence of polarization-specific changes of the cellular cytoskeleton (McWhorter et al., 2013). The only morphological feature observed in both, M1 and M2 populations of MФs, is that they are moderately dendritic, possibly because such MФs are in the process of polarization, prior to cytoskeletal changes (Sica and Mantovani, 2012), or because polarization in MФs is reversible polarizing (Sica and Mantovani, 2012; Yuan et al., 2017). Future studies should characterise the influence of cytoskeletal changes on TPE-FLIM parameters in detail and use TPE-FLIM to assess the impact of age, gender, and disease on the ratio, localization and function of M1 and M2 MФs in the skin (Fukui et al., 2018).

During phagocytosis, the generation of ROS by NAD $(\mathrm{P}) \mathrm{H}$ oxidase leads to the highest degree of metabolic stress observed in M1 MФs besides apoptosis (Dupré-Crochet et al., 2013; Shirshin et al., 2019), and ROS localization in vacuoles in phagocytosing M1 MФs as a bactericidal mechanism (Dupré-Crochet et al., 2013; Myers et al., 2003). This is why phagocytosing M1 MФs change their TPE-FLIM lifetimes towards shorter values and their vacuoles become visible as localised bright spots, which makes their in vivo detection possible (Fig. 5b, Table 1) (Cannon and Swanson, 1992). TPE-FLIM allowed for the detection of phagocytosing M1 MФs but cannot detect what they phagocytised. No internal structure was visible in TPE-FLIM images.

The construction of the feature vector and the resulting hyperparameter optimised decision tree model (Fig. S6) yielded proficient results for the automatised classification of M1 and M2 MФs, demonstrating that M1 and M2 MФs can be separated from each other and other cells in the skin with high accuracy, i.e. sensitivity and specificity, without need of additional staining using a supervised machine learning approach. The accuracy of this approach can be improved further, by the introduction of a depth-adjusted cell size and refined cell shape parameters and by increasing the number of in vivo MФs integrated into the algorithm and training data set.

\section{Materials and Methods}

\section{Two-photon excited fluorescence lifetime imaging (TPE-FLIM)}

For imaging of human MФs, a two-photon tomograph (Dermainspect, JenLab GmbH, Jena, Germany), equipped with a tuneable femtosecond Ti:sapphire laser (Mai Tai XF, Spectra Physics, USA, 710-920 nm, $100 \mathrm{fs}$ pulses at a repetition rate of $80 \mathrm{MHz}$ ), was used at 3-5 $\mathrm{mW}$ for measurements of cells in vitro and skin biopsy sections ex vivo, as well as human dermis in vivo at 40-50 $\mathrm{mW}$. The excitation wavelength was set to $760 \mathrm{~nm}$, and a 410-680 $\mathrm{nm}$ band pass filter was used to detect two-photon excited autofluorescence (TPE-AF), whereas a 375-385 $\mathrm{nm}$ band pass filter was used to detect the second harmonic generation (SHG) signals. The axial and lateral resolution was approximately $1.2-2.0$ and $0.5 \mu \mathrm{m}$, respectively(Breunig et al., 2013). The penetration depth covers the entire papillary dermis (Darvin et al., 2014; König, 2008; Kröger et al., 2020). 
Fluorescence decay of a specimen was recorded and analysed in the SPCImage 8.0 software (Becker\&Hickl, Berlin, Germany). TPE-FLIM data were fitted with a bi-exponential decay function. The TPE-AF intensity threshold was chosen depending on the signal-to-noise ratio, minimizing noise in the region of interest. The shift of the signal in relation to the instrument response function (IRF) was compensated. The typical IRF value was <100 ps. The TPE-AF decay curves were averaged over the central pixel of the region of interest and the 48 closest square neighbouring pixels (binning $=3$ ), resulting in a number of detected photons for each fluorescence decay curve larger than 5,000. The TPE-AF decay parameters, decay lifetimes $\left(\tau_{1}\right.$ and $\left.\tau_{2}\right)$ and amplitudes $\left(a_{1}\right.$ and $\left.a_{2}\right)$, were used for the evaluation of the fluorescence lifetime distributions and 2D segmentation(Shirshin et al., 2017). The analysed parameters were the mean lifetime, defined as $\tau_{m}=\left(a_{1} \tau_{1}+a_{2} \tau_{2}\right) /\left(a_{1}+a_{2}\right)$ and the ratios $\tau_{2} / \tau_{1}, a_{1} / a_{2}$ and $\left(a_{1}-a_{2}\right) /\left(a_{1}+a_{2}\right)$, which were used for $2 \mathrm{D}$ segmentation analysis. The TPE-FLIM data were also analysed and represented as phasor plots, that are based on the transformation of the fluorescence decay data in the frequency domain, whereas the decay is described as amplitude and phase values of the first Fourier component(Digman et al., 2008). The phasor plots' $x$-axis is described by the cosine of the phase value multiplied by the amplitude, the $y$-axis represents the sine of the phase value multiplied with the amplitude(Lakner et al., 2017; Shirshin et al., 2019). The position of the mean lifetime is on the secant from $\tau_{1}$ and $\tau_{2}$, the distance to the circle is given by the proportion of $a_{1}$ and $a_{2}$. The TPE-FLIM data were normalised to the maximum intensity and the threshold of $70 \%$ was set when analysing the phasor plots.

\section{Ethical considerations and study conduct}

Volunteers for intravital imaging provided written informed consent before participation. Skin samples taken from periocular skin surgery for MФ preparation and all human skin investigated in this study were used after written informed consent was obtained. Positive votes for the experiments have been obtained from the ethics committee of the Charite Universitätsmedizin Berlin (EA1/078/18, EA4/193/18, EA1/141/12), which were conducted according to the Declaration of Helsinki (59th WMA General Assembly, Seoul, October 2008).

\section{Study subjects}

25 healthy volunteers (12 males and 13 females, 24-65 years old, skin type I-III according to Fitzpatrick classification(Fitzpatrick, 1988)) with asymptomatic volar forearm skin without preexisting health conditions were randomly selected for non-invasive in vivo measurements in the papillary dermis using TPE-FLIM. Visually impairing hair was removed with a scissor prior to measurements. The oil immersion objective of the microscope was connected to the skin via a $150 \mu \mathrm{m}$ thick, $18 \mathrm{~mm}$ diameter cover glass (VWR, Darmstadt, Germany) with a $\approx 10 \mu \mathrm{L}$ distilled water droplet between cover glass and skin. The volunteers were screened between October 2018 and November 2020.

\section{Investigation of human dermal M\$s in vitro}

Human dermal MФs were prepared from periocular tissue(Botting et al., 2017). Human periocular skin was digested in $2.4 \mathrm{U} / \mathrm{ml}$ dispase type II (Roche, Basel, Switzerland) at $4{ }^{\circ} \mathrm{C}$ for 12 hours. The dermis was minced with scissors after removal of the epidermis and further digested in PBS containing $\mathrm{Ca}^{2+}$ and $\mathrm{Mg}^{2+}$ (Gibco, Carlsbad, CA, USA) supplemented with $1 \%$ Pen/Strep, $5 \%$ FCS, $5 \mathrm{mM} \mathrm{MgSO}_{4}, 10 \mu \mathrm{g} / \mathrm{ml}$ DNaseI (Roche, Basel, 
Switzerland), $2.5 \mu \mathrm{g} / \mathrm{ml}$ amphothericin (Biochrom, Berlin, Germany,) $1.5 \mathrm{mg} / \mathrm{ml}$ collagenase type II (Worthington Biochemical Corp., Lakewood, NJ, USA) and $0.75 \mathrm{mg} / \mathrm{ml}$ $\mathrm{H}-3506$ hyaluronidase (Sigma-Aldrich, St. Louis, MO, USA) at $37^{\circ} \mathrm{C}$ in a water bath with agitation for $60 \mathrm{~min}$. The cell suspension was filtered using $300 \mu \mathrm{m}$ and $40 \mu \mathrm{m}$ stainless steel sieves (Retsch, Haan, Germany). Centrifugation at $300 \times \mathrm{g}$ for $15 \mathrm{~min}$ at $4{ }^{\circ} \mathrm{C}$ was applied next. The digestion cycle was repeated once. MФs were isolated by Pan Monocyte Isolation Kit (Miltenyi, Bergisch Gladbach Germany) after washing in PBS w/o Ca ${ }^{2+}$ and $\mathrm{Mg}^{2+}$ (Gibco, Carlsbad, CA, USA), and kept in basal Iscove's medium supplemented with $1 \%$ Pen/Strep, $10 \%$ FCS, $1 \%$ non-essential amino acids, $226 \mu \mathrm{M} \alpha$-monothioglycerol (all Gibco, Carlsbad, CA, USA). For long-term cultures, after $24 \mathrm{~h}$ recombinant human IL-4 (20 $\mathrm{ng} / \mathrm{ml})$ and $\mathrm{hSCF}(100 \mathrm{ng} / \mathrm{ml}$ ) (both Peprotech, Rocky Hill, NJ, USA) were added. Purity of MФ cultures was routinely checked to be $>85 \%$ (Nielsen et al., 2020). For imaging, cells were used after 3 days in medium, washed twice with PBS before seeding on $18 \mathrm{~mm}$ diameter microscope cover glass (VWR, Darmstadt, Germany) for imaging in PBS containing $\mathrm{Ca}^{2+}$ (Gibco, Carlsbad, CA, USA) at room temperature.

\section{Investigation of peripheral blood monocytes in vitro}

Peripheral blood monocytes were isolated from human blood using $15 \mathrm{ml}$ Ficoll-Paque (VWR, Darmstadt, Germany) centrifugation gradient. Centrifugation was performed at $1,000 \times \mathrm{g}$ for 1 minute, with added $9 \mathrm{ml}$ heparin and filled to $50 \mathrm{ml}$ with PBS. Centrifugation was then repeated at $1,000 \mathrm{~g}$ for 10 minutes, discarding the upper plasma layer and collecting the PBMC layer. The cells were washed twice with PBS and centrifuged at 350 $\times \mathrm{g}$ for 10 minutes. The supernatant was discarded and cultured in $5 \mathrm{ml}$ basal Iscove's medium supplemented with $1 \%$ Pen/Strep, 10\% FCS (Biochtrom, Berlin, Germany) and subsequently incubated at $37{ }^{\circ} \mathrm{C}$ and $5 \% \mathrm{CO}_{2}$ for $2 \mathrm{~h}$ before seeded and imaged on an 18 mm diameter microscope cover glass (VWR, Darmstadt, Germany) in PBS containing $\mathrm{Ca}^{2+}$ (Gibco, Carlsbad, CA, USA) at room temperature.

\section{Investigation of MФs differentiated from peripheral blood monocytes in vitro}

MФs were differentiated from peripheral blood monocytes and polarised into M1 (IFN $\gamma$ )like state with M $\Phi$ colony-stimulating factor (M-CSF) and IFN $\gamma$ and M2 (IL-4)-like state with MФ colony-stimulating factor (M-CSF) and IL-4. For further stimulation, cells were incubated with LPS at $37^{\circ} \mathrm{C}$ for 24 hours prior to imaging.

\section{Investigation of dendritic cells in vitro}

CD14 positive peripheral blood mononuclear cells were used to differentiate dendritic cells by washing in PBS and centrifuging at $350 \times \mathrm{g}$ for 10 minutes twice. $5 \mathrm{ml}$ RPMI medium, supplemented with 1\% Pen/Strep and 1\% FCS (Biochtrom, Berlin, Germany), was added. Tryptan Blue (Sigma-Aldrich, St. Louis, MO, USA) was used for counting the cells in a hemocytometer, seeded at $2.0 \times 10^{6}$ cells $/ \mathrm{ml}$ and incubated for 2 hours at $37^{\circ} \mathrm{C}$ under $5 \%$ $\mathrm{CO}_{2}$. Non-attached cells and the supernatant were discarded. Adding $500 \mu 1$ basal Iscove's medium to the cells supplemented with $1 \%$ Pen/Strep, $1 \%$ glutamine, 5\% HSA, (all Gibco, Carlsbad, CA, USA) 100 ng/ml IL-4, 100 ng/ml GM-CSF (both Peprotech, Rocky Hill, NJ, USA) with medium change every second day for 6 days at $37^{\circ} \mathrm{C}$. For TPE-FLIM imaging the cells were seeded on $18 \mathrm{~mm}$ diameter microscope cover glass (VWR, Darmstadt, Germany) in PBS containing $\mathrm{Ca}^{2+}$ at room temperature. 


\section{Preparation and cryo-sectioning of human skin for combined TPE-FLIM and histomorphometric analysis}

Thirteen human skin biopsy cryo-sections were prepared and measured using the TPEFLIM method to acquire TPE-FLIM parameters of suspected M1 and M2 MФs. The skin biopsies were obtained from abdominal reduction surgery of four female patients $(31,33$, 40 and 44 y. o., skin type II according to Fitzpatrick classification(Fitzpatrick, 1988)). Punch biopsies of $6 \mathrm{~mm}$ diameter were obtained, frozen and stored at $-80{ }^{\circ} \mathrm{C}$ before cryosectioning. Vertical histological cryo-sections of $10 \mu \mathrm{m}$ thickness were prepared on a cryostat (Microm Cryo-Star HM 560, MICROM International GmbH, Walldorf, Germany) after embedding in a cryo-medium (Tissue Freezing Medium, Leica Biosystems Richmond Inc., Richmond, IL, USA) and placed on $18 \mathrm{~mm}$ diameter microscope cover glasses (VWR, Darmstadt, Germany). The anatomical condition of the biopsies was continuously examined using a transmission microscope (Olympus IX 50, Olympus K.K., Shinjuku, Tokyo, Japan).

Using TPE-FLIM, cryo-sections were searched for cells with MФ-specific TPE-FLIM parameters and the corresponding TPE-FLIM images of suspected MФs were recorded. To prove the measured cells are MФs, the skin biopsies were labeled by irradiating a squared area of $28 \mu \mathrm{m} \times 28 \mu \mathrm{m}$ located near the suspected MФs with a Ti:sapphire laser (Mai Tai XF, Spectra Physics, USA, $100 \mathrm{fs}$ pulses at a repetition rate of $80 \mathrm{MHz}$ ) at a maximal power of $50 \mathrm{~mW}$ at $760 \mathrm{~nm}$ for 3 seconds. All incubations were performed at room temperature unless otherwise stated. In brief, sections were fixed for $10 \mathrm{~min}$ in cold acetone $\left(-20^{\circ} \mathrm{C}\right)$ and rinsed in TBS (Agilent, Santa Clara, CA, USA). For staining of MФs, the MФ-specific anti-CD68 (clone ab955) (Abcam, Cambridge, UK), Recombinant Anti-CD163 antibody [EPR1464336] (clone ab189915) (Abcam, Cambridge, UK) were used to account for M1 and M2 MФ phenotypes, respectively. Slides were rinsed three times with TBS, and endogenous peroxidase was blocked with $3 \% \mathrm{H}_{2} \mathrm{O}_{2}$ in TBS for 5 min followed by incubation with antimouse EnVision+ labelled polymer (Agilent Technologies, Santa Clara, USA) for 30 min. Slides were rinsed in TBS as before and incubated with AEC substrate-chromogen (Agilent Technologies, Santa Clara, USA) for $10 \mathrm{~min}$. Nuclei were counterstained with Mayer's hemalum solution (Merck, Darmstadt, Germany). Stained MФs have a brown-red color, which enables to visually distinguish them from other cells and the ECM. After the staining procedure, target MФs and squared labels of the skin sections were identified by light microscopy and overlaid with TPE-FLIM images matching an appropriate magnification and image orientations.

Specifically, CD68-stained M1 MФs were counted in the papillary dermis region in each biopsy, and an average of $209 \pm 25$ cells $/ \mathrm{mm}^{2}$ for the papillary dermis and an average of $140 \pm 76$ cells $/ \mathrm{mm}^{2}$ for the reticular dermis for a $10 \mu \mathrm{m}$ deep cryo-section was observed (Fig. 1c). The density of the CD163 stained M2 MФs was an average of $242 \pm 126$ cells $/ \mathrm{mm}^{2}$ for the papillary dermis and an average of $107 \pm 60 \mathrm{cells} / \mathrm{mm}^{2}$ for the reticular dermis for a 10 $\mu \mathrm{m}$ deep cryo-section (Fig. 1d).

The MФs search algorithm we then used was similar to that recently presented by our group for the identification of resting and activated mast cells in the papillary dermis(Kröger et al., 2020) and included the following steps: First, the papillary dermis $(\approx 60-100 \mu \mathrm{m}$ depth for volar forearm) was explored for fluorescent spots of $10-15 \mu \mathrm{m}$ in size with irregular shape and a membrane extension having bright spots of about 1-3 $\mu \mathrm{m}$. The TPE-FLIM parameters of the suspected bright areas were measured and matched those of M1 and M2 MФs obtained in vitro and ex vivo.

To prove that the TPE-FLIM parameters of other dermal cells, which have detectable TPEAF intensity, namely, mast cells and dendritic cells do not match or superimpose with TPE- 
FLIM parameters of MФs, negative control measurements were performed. The procedure was similar as described for the verification of MФs in skin biopsies using specific immunofluorescence, but six human skin cryo-sections were stained for the presence of mast cells and two for dendritic cells.

Staining of mast cells was done by blocking with serum-free protein followed by incubation for $1 \mathrm{~h}$ with anti-tryptase antibody (clone AA1) diluted 1:1,000 in antibody diluent (all Agilent, Santa Clara, CA, USA). For staining of dendritic cells, anti-CD11c antibody (clone B-Ly6) (BD Biosciences, Franklin Lakes, NJ, USA) was used after fixing the cryo-section for $10 \mathrm{~min}$ in cold acetone $\left(-20^{\circ} \mathrm{C}\right)$ and rinsing with TBS.

\section{Statistical analysis and classification algorithm}

Matlab R2016a (MathWorks, Natick, MA, USA) was applied for descriptive statistics of all TPE-FLIM data. All results are indicated as mean \pm standard deviation. Differences between distributions were compared using the non-parametric Kolmogorov-Smirnov test with a significance level of $\alpha=0.05$. The decision tree classifier was modelled using Scikit-learn 0.22 in a Python 3.7 environment (Python Software Foundation, Delaware, USA). A randomised training set, consisting of $50 \%$ of the complete data set, was used for training and validating the test set 10,000 times. The true positive- and true negative rates were calculated from the confusion matrix and describe the quality of the classification and indicate type I and type II errors. For the decision tree(Breiman et al., 1984), the TPE-FLIM parameters $\tau_{1}, \tau_{2}, \tau_{m}, \tau_{1} / \tau_{2}, a_{1}, a_{2}, a_{1} / a_{2},\left(a_{1}-a_{2}\right) /\left(a_{1}+a_{2}\right)$, TPE-AF intensity, cell shape, and decay curve were used for each cell measured in vitro, ex vivo, and in and hyperparametrically optimized(Yang and Shami, 2020). The feature vector was constructed as follows: 1 (shape (circular form)) +1 (normalised TPE-AF intensity of cell normalised by the cell's area and excitation power) +256 (fluorescence decay curve) +8 (TPE-FLIM parameters obtained after bi-exponential approximation of the decay curve), in total, 266 values. The MФ size was not included in the feature vector for the classification model, as MФs in vivo could have slightly different dimensions from those measured in vitro (in cell cultures) and ex vivo (in biopsies), caused by obscuring effects of surrounding dermal tissue. Here, 1 represents circular and 0 non-circular shape. The lifetimes calculated from the biexponential decay model were averaged over the whole cell, and the fluorescence intensity was normalised by optical power and averaged the pixel of interest and the 48 neighbouring square pixel.

In total, $110 \mathrm{M \Phi s} \mathrm{in} \mathrm{vitro,} 20 \mathrm{M \Phi s} \mathrm{ex} \mathrm{vivo,} 70 \mathrm{M \Phi s}$ in vivo (for M1/M2 ratio see Table 1), 59 mast cells in vitro, 17 mast cells ex vivo, 82 mast cells in vivo, 14 dendritic cells in vitro, 6 fibroblasts in vitro and 21 neutrophils in vitro were used as input for the model $(399$ cells in total). Given data vectors from $x_{i} \in R^{n}, i=1, \ldots, l$ and a label vector $y_{i} \in R^{l}$, where a decision tree recursively separates the data into two classes with the mode $m$ represented as $Q$. For each node a split $\theta=\left(j, t_{m}\right)$ decided with the feature $j$ and the threshold $t_{m}$. The node split the data into subsets $Q_{\text {left }}(\theta)$ and $Q_{\text {right }}(\theta)$

$$
\begin{gathered}
Q_{\text {left }}(\theta)=(x, y) \mid x_{j}<=t_{m} \\
Q_{\text {right }}(\theta)=Q \backslash Q_{\text {right }}(\theta)
\end{gathered}
$$

The impurity was calculated by the impurity function $H()$ at the mode $m$

$$
G(Q, \theta)=n_{\text {left }} / N_{m} H\left(Q_{\text {left }}(\theta)\right)+{ }^{n_{\text {right }}} / N_{m} H\left(Q_{\text {right }}(\theta)\right)
$$


612 With the parameters for minimised impurities the subsets were recourse until $N_{m}=1$.

613

614

615

616

617

618

619

620

621

622

623

624

625

626

627

628

629

630

631

632

633

634

635

636

637

638

639

640

641

642

643

644

645

646

647

648

649

650

651

652

653

654

655

656

657

658

659

660

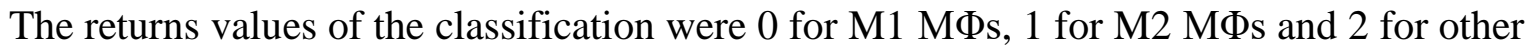
dermal cells, 0 for MФs and 1 for other dermal cells for node $m$ in the region $R_{m}$ and $N_{m}$ observation, the proportion of class $k$ observations in node $m$ is $p_{m k}=1 / N_{m} \sum_{x_{i} \in R_{m}} I\left(y_{i}=\right.$ $k)$.

Receiver operating characteristic (ROC)-curves served as a tool to determine the diagnostic abilities of the method, where the true positive rate was plotted against the false positive rate of the respective outcomes for both the categorization of MФs against other dermal cells and M1 MФs and M2 MФs against other dermal cells. 


\section{Supplementary Materials}
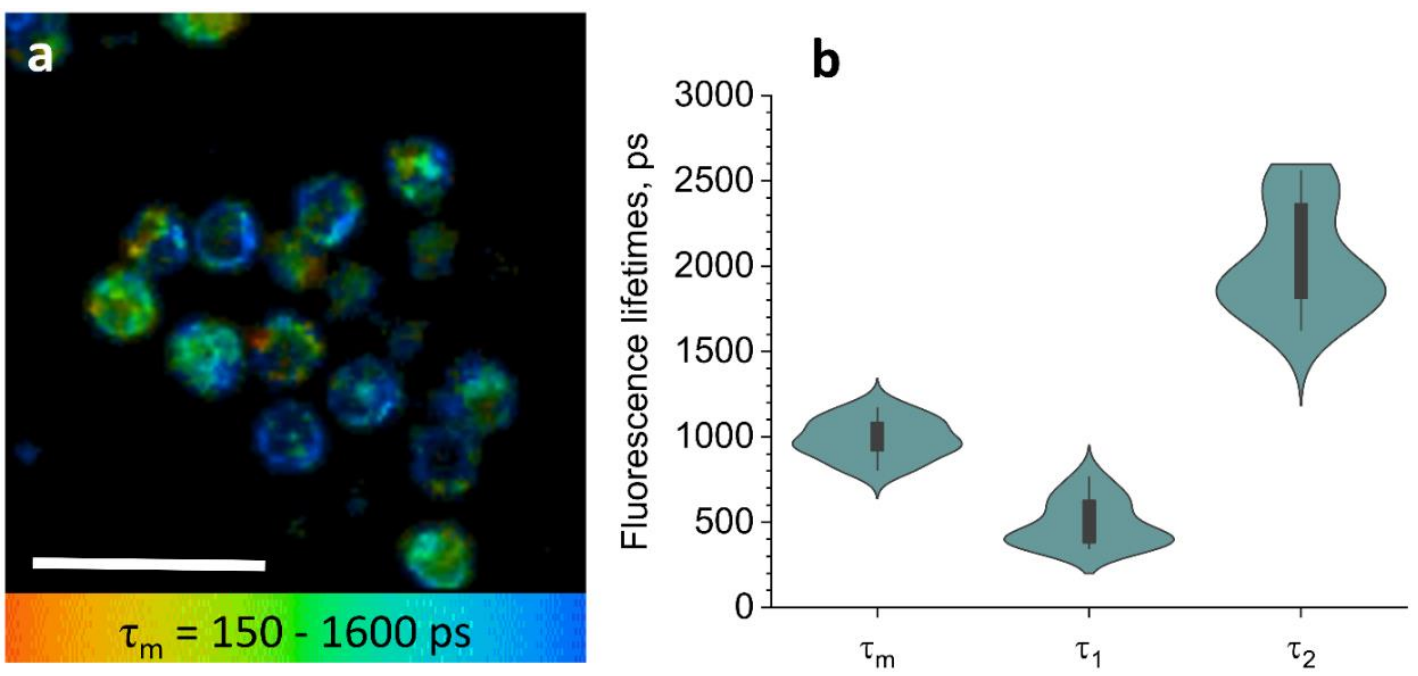

Fig. S1. TPE-FLIM visualisation of PBMC and histogram of TPE-FLIM parameter. TPEFLIM $\tau_{m}$ images (mean fluorescence lifetime $\tau_{m}$ in the 150-1,600 ps range) of PBMC (a) Scale bar: $10 \mu \mathrm{m}$. The distribution of TPE-FLIM parameters $\tau_{1}, \tau_{2}$ and $\tau_{m}$ for PBMC ( $\left.n=15\right)$ (f).

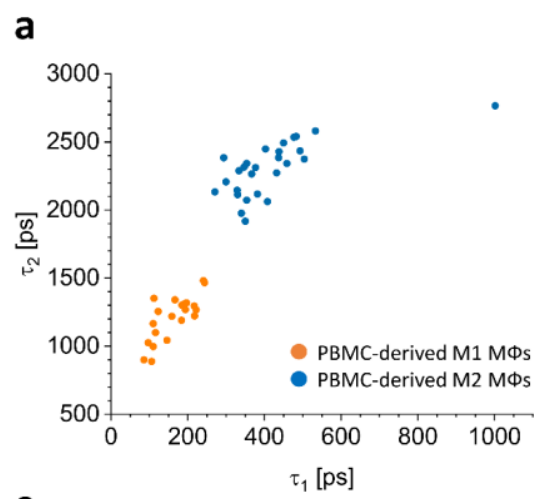

C

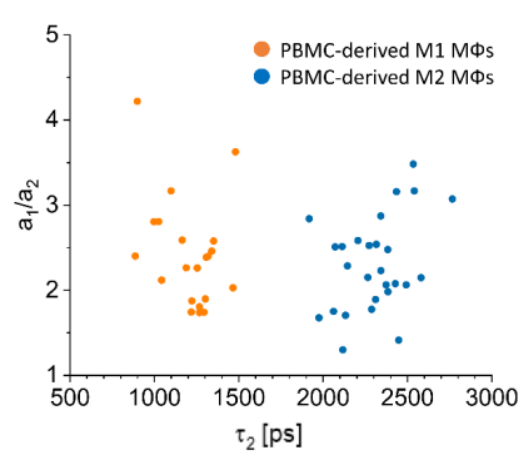

b

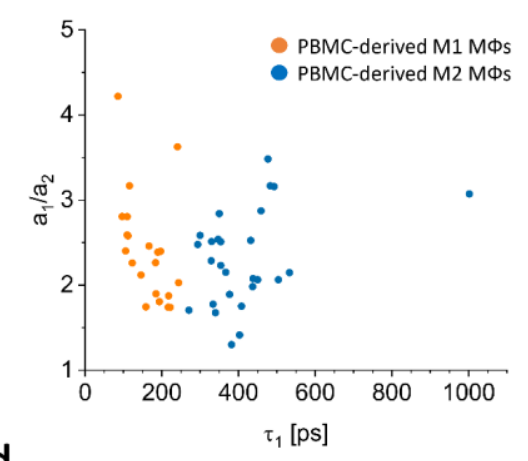

d

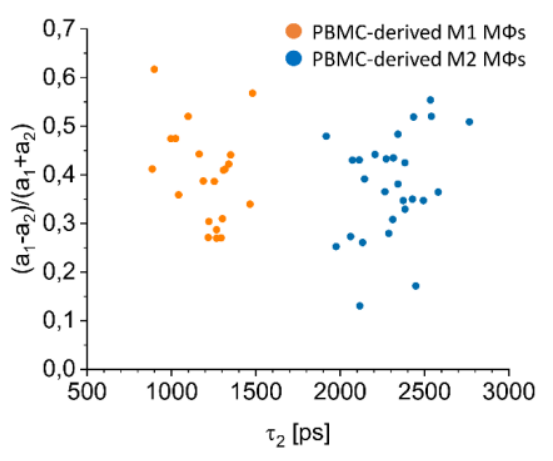

Fig. S2. In vitro 2D segmentation for MФs from PBMC. 2D segmentation of the $\tau_{1}\left(\tau_{2}\right)$ (a), $\tau_{1}\left(a_{1} / a_{2}\right)(\mathrm{b}), \tau_{2}\left(a_{1} / a_{2}\right)$ (c) and $\tau_{2}\left(\left(a_{1}-a_{2}\right) /\left(a_{1}+a_{2}\right)\right)$ (d) TPE-FLIM parameters of the M1 MФs (orange circles) and M2 MФs (blue circles) measured in vitro. 
a

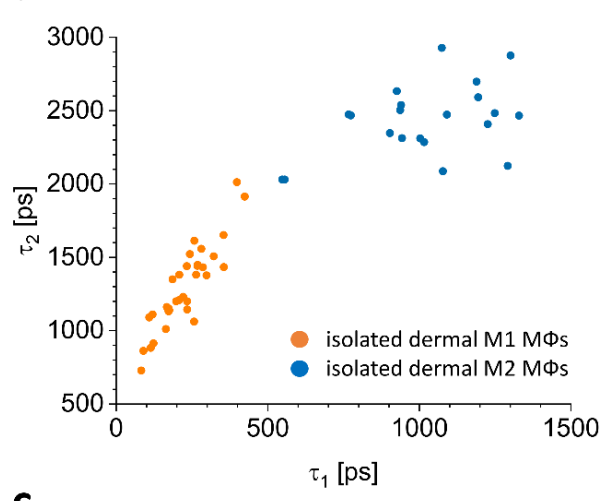

C

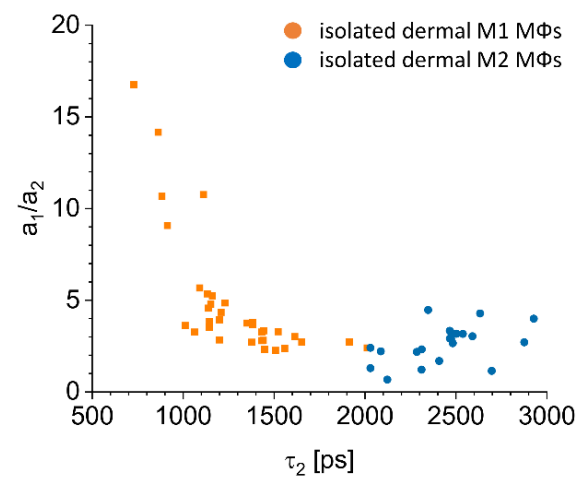

b

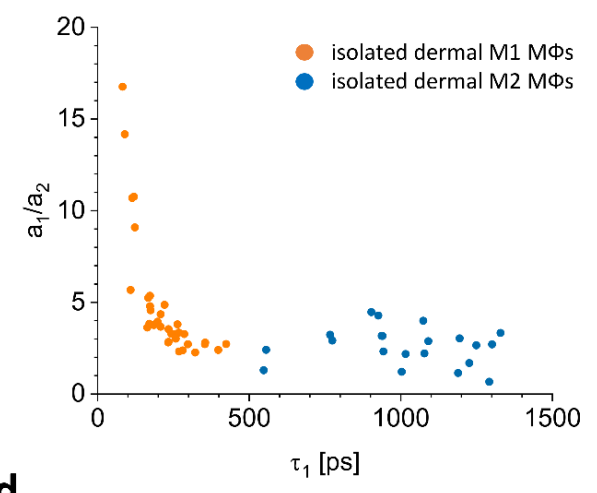

d

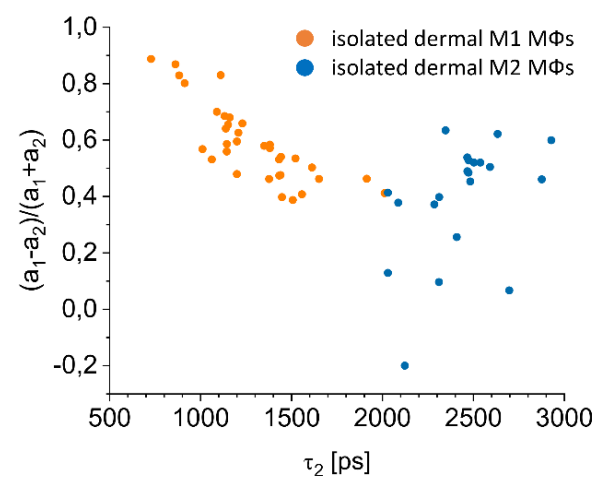

675

676

677

678

679

Fig. S3. In vitro segmentation for MФs from dermal tissue. 2D segmentation of the $\tau_{1}\left(\tau_{2}\right)$ (a), $\tau_{1}\left(a_{1} / a_{2}\right)(\mathrm{b}), \tau_{2}\left(a_{1} / a_{2}\right)(\mathrm{c})$ and $\tau_{2}\left(\left(a_{1}-a_{2}\right) /\left(a_{1}+a_{2}\right)\right)$ (d) TPE-FLIM parameters of the M1 MФs (orange circles) and M2 MФs (blue circles) measured in vitro. 
a

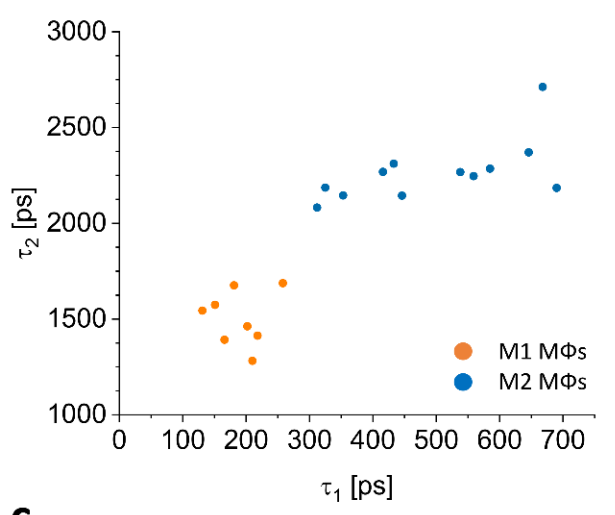

C

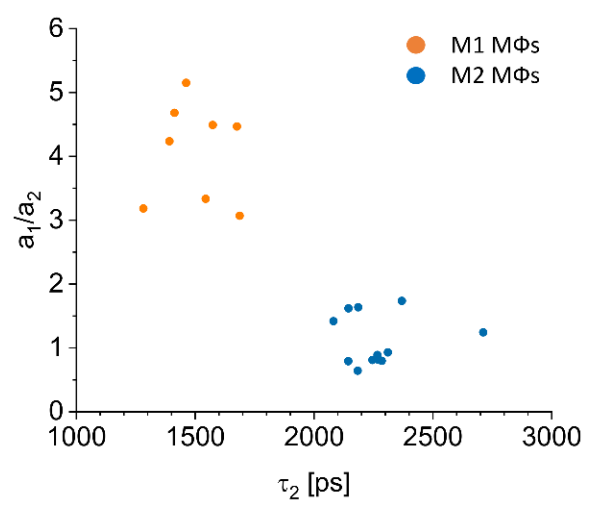

b

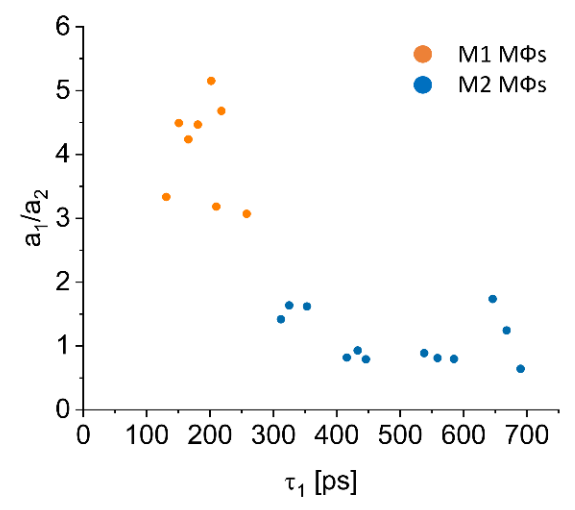

d

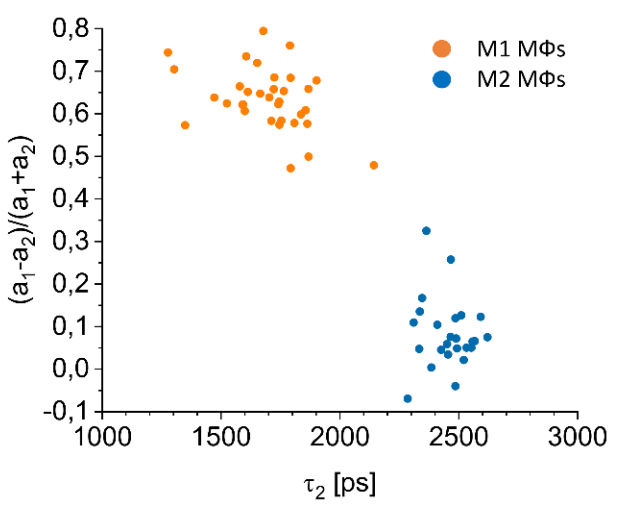

681 Fig. S4. Ex vivo segmentation for MФs from skin biopsies. 2D segmentation of the $\tau_{l}\left(\tau_{2}\right)(\mathrm{a})$, $682 \tau_{1}\left(a_{1} / a_{2}\right)(\mathrm{b}), \tau_{2}\left(a_{1} / a_{2}\right)(\mathrm{c})$ and $\tau_{2}\left(\left(a_{1}-a_{2}\right) /\left(a_{1}+a_{2}\right)\right)(\mathrm{d})$ TPE-FLIM parameters of the M1 MФs (orange 683 circles) and M2 MФs (blue circles) measured ex vivo. 
a

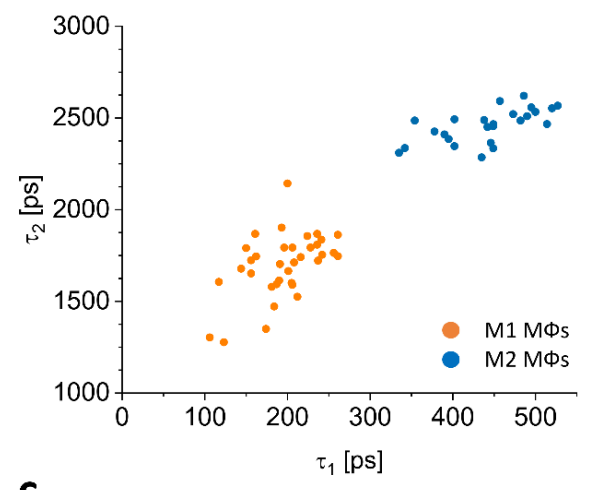

C

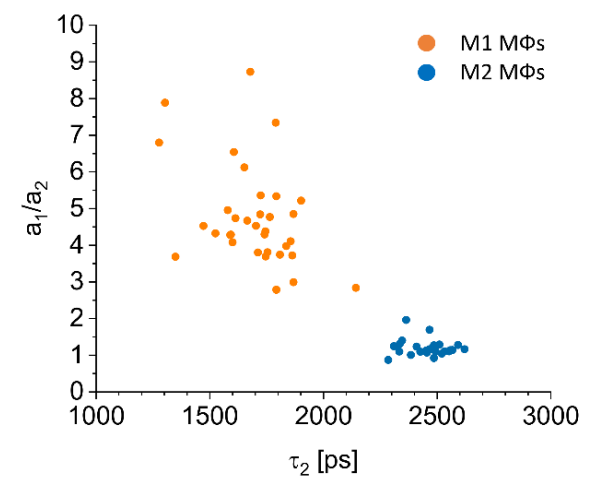

b

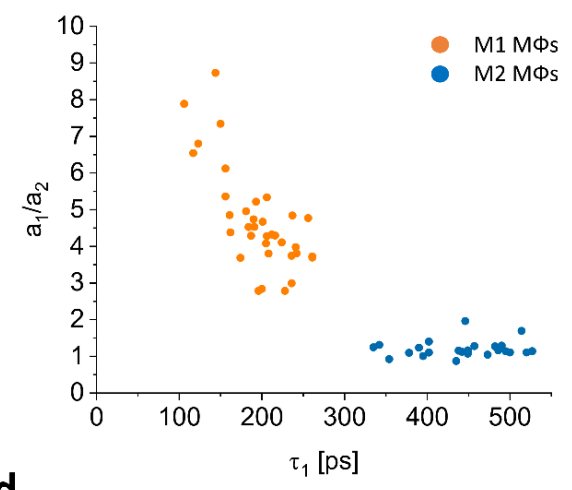

d

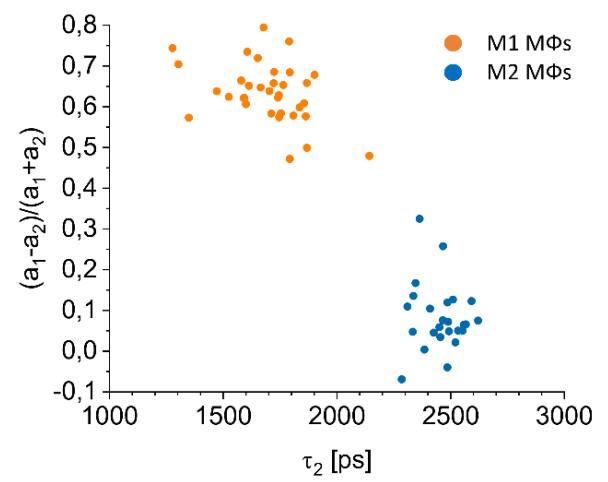

686 Fig. S5. In vivo segmentation for MФs in human skin. 2D segmentation of the $\tau_{1}\left(\tau_{2}\right)(\mathrm{a}), \tau_{1}\left(a_{1} / a_{2}\right)$ 687 (b), $\tau_{2}\left(a_{1} / a_{2}\right)$ (c) and $\tau_{2}\left(\left(a_{1}-a_{2}\right) /\left(a_{1}+a_{2}\right)\right)$ (d) TPE-FLIM parameters of the M1 MФs (orange circles) 688 and M2 MФs (blue circles) measured in vitro. 


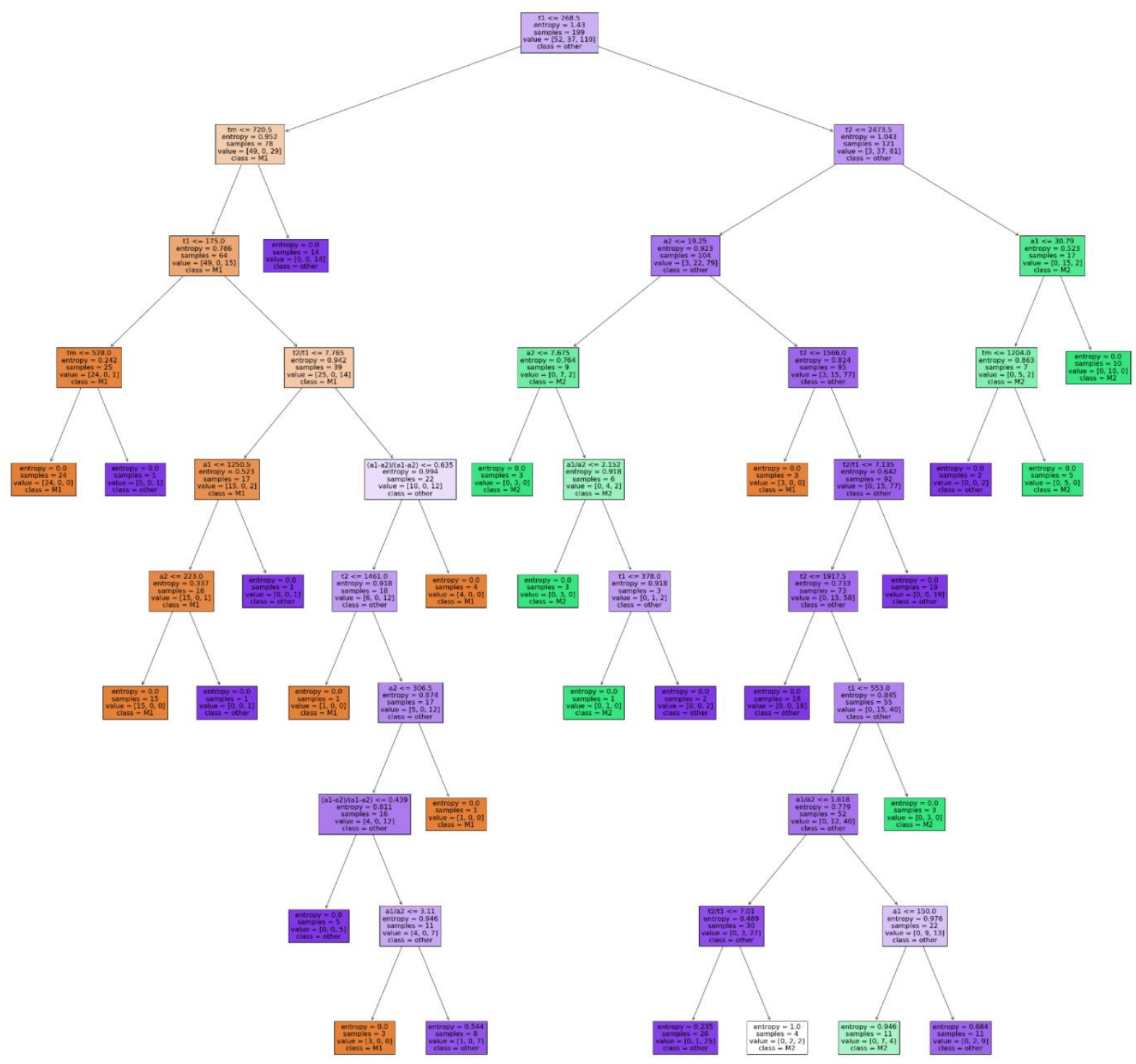

691 Fig. S6. Decision tree model. Decision tree model for classification of M1 and M2 MФs with the 692 parameters entropy impurity, minimal samples for split is 2, maximum depth of the tree is 9 , and 693 the samples had equal weight. The text of the decision tree is readable when zoomed in. 
a

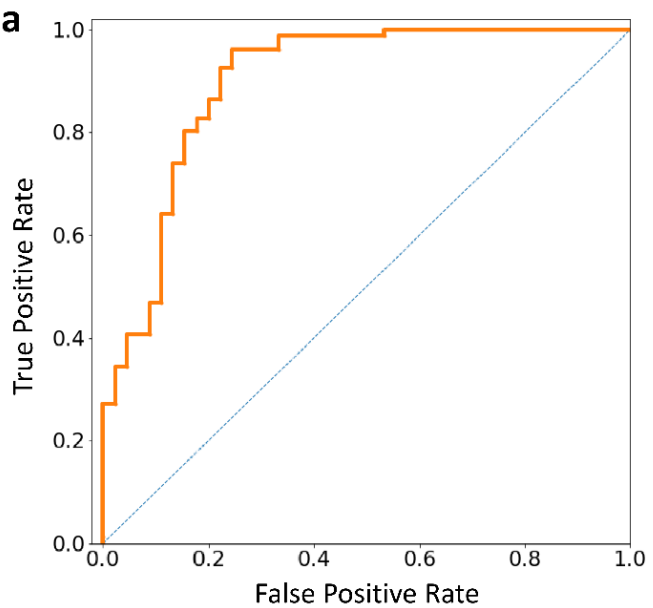

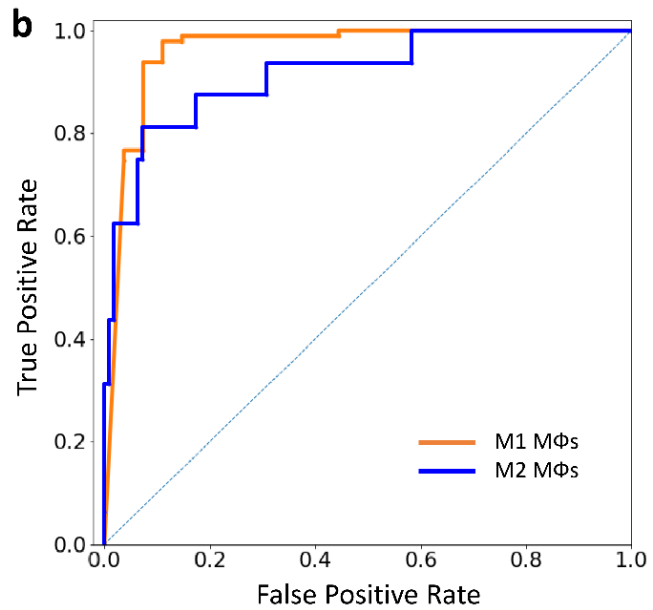
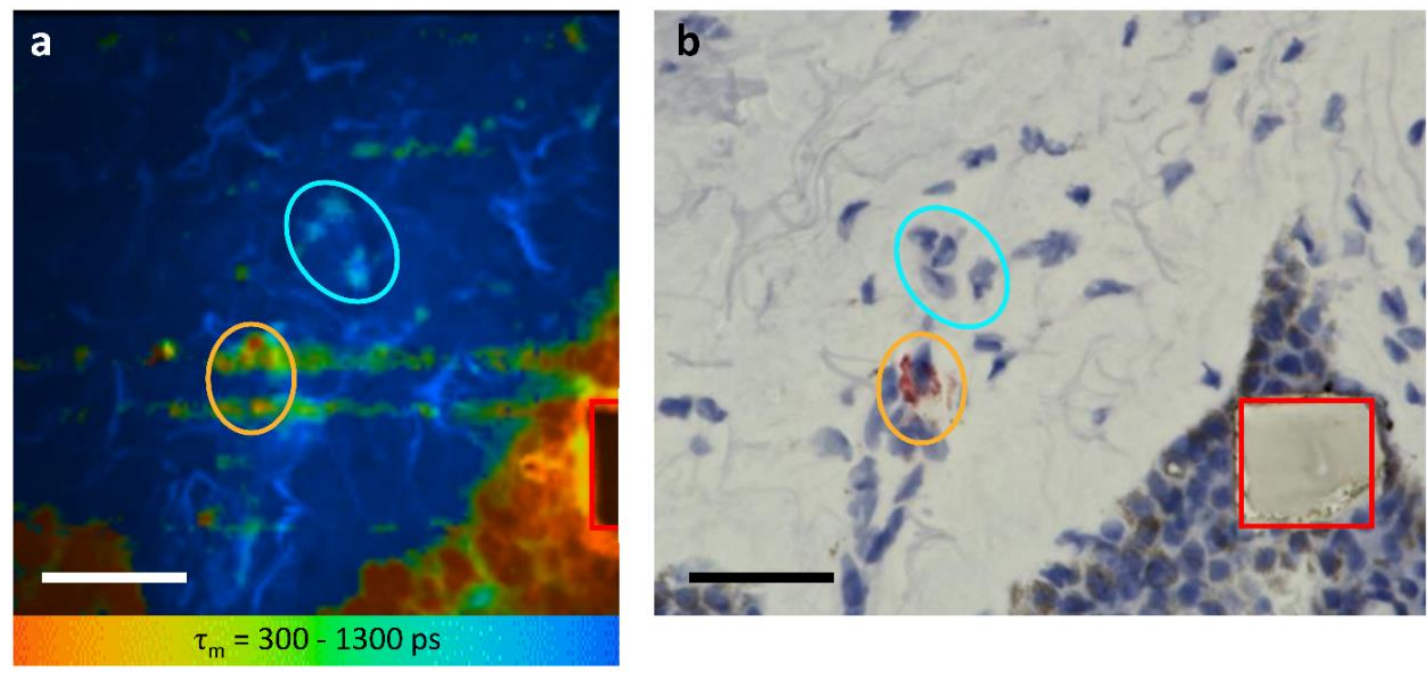

Fig. S8. Mast cell-specific staining with tryptase ex vivo - negative control. Side by side comparison of TPE-FLIM image (average lifetime $\tau_{m}$ in the 300-1,300 ps range) (a) and corresponding light microscopic image after staining of human skin biopsy cryo-sections for MCs (b). Laser power is $3 \mathrm{~mW}$, excitation at $760 \mathrm{~nm}$. The MCs are marked with orange ellipses, suspected MФs are marked with blue ellipses, and the laser burned squares $\left(28 \times 28 \mu \mathrm{m}^{2}\right)$ used for labeling are marked in red. Images have been rotated and zoomed to match the same orientation and size. Scale bar: $30 \mu \mathrm{m}$.

Fig. S7. ROC curves of decision tree models. ROC curves of false positive to false negative rates

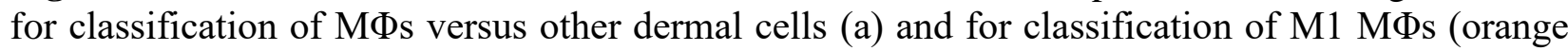
line) versus M2 MФs and other dermal cells and for classification of M2 MФs (blue line) versus M1 MФs and other dermal cells (b) generated from the decision tree classifier (Fig. S6). 


\section{References}

Al-Shabany AJ, Moody AJ, Foey AD, Billington RA. 2016. Intracellular NAD+ levels are associated with LPS-induced TNF- release in pro-inflammatory macrophages. Biosci Rep 36:e0301-e00301. doi:10.1042/bsr20150247

Alfonso-García A, Smith TD, Datta R, Luu TU, Gratton E, Potma EO, Liu WF. 2016. Label-free identification of macrophage phenotype by fluorescence lifetime imaging microscopy. $J$ Biomed Opt 21:046005. doi:10.1117/1.jbo.21.4.046005

Benoit M, Desnues B, Mege J-L. 2008. Macrophage Polarization in Bacterial Infections. J Immunol 181:3733-3739. doi:10.4049/jimmunol.181.6.3733

Blacker TS, Mann ZF, Gale JE, Ziegler M, Bain AJ, Szabadkai G, Duchen MR. 2014. Separating NADH and NADPH fluorescence in live cells and tissues using FLIM. Nat Commun 5:3936. doi:10.1038/ncomms4936

Botting RA, Bertram KM, Baharlou H, Sandgren KJ, Fletcher J, Rhodes JW, Rana H, Plasto TM, Wang XM, Lim JJK, Barnouti L, Kohout MP, Papadopoulos T, Merten S, Olbourne N, Cunningham AL, Haniffa M, Harman AN. 2017. Phenotypic and functional consequences of different isolation protocols on skin mononuclear phagocytes. J Leukoc Biol 101:1393-1403. doi:10.1189/jlb.4a1116-496r

Breiman L, Friedman JH, Olshen RA, Stone CJ. 1984. Classification and regression trees, The Wadsworth statistics/probability series. Monterey, CA: Wadsworth \& Brooks/Cole Advanced Books \& Software.

Breunig HG, Weinigel M, Bückle R, Kellner-Höfer M, Lademann J, Darvin ME, Sterry W, König K. 2013. Clinical coherent anti-Stokes Raman scattering and multiphoton tomography of human skin with a femtosecond laser and photonic crystal fiber. Laser Phys Lett 10:025604. doi:10.1088/1612-2011/10/2/025604

Cannon GJ, Swanson JA. 1992. The macrophage capacity for phagocytosis. J Cell Sci 101:907913. doi:10.1242/jcs.101.4.907

Cheng J, Zhang Q, Fan S, Zhang A, Liu B, Hong Y, Guo J, Cui D, Song J. 2019. The vacuolization of macrophages induced by large amounts of inorganic nanoparticle uptake to enhance the immune response. Nanoscale 11:22849-22859. doi:10.1039/c9nr08261a

Colin-York H, Li D, Korobchevskaya K, Chang VT, Betzig E, Eggeling C, Fritzsche M. 2019. Cytoskeletal actin patterns shape mast cell activation. Commun Biol 2:1-12. doi:10.1038/s42003-019-0322-9

Darvin ME, Richter H, Ahlberg S, Haag SF, Meinke MC, Le Quintrec D, Doucet O, Lademann J. 2014. Influence of sun exposure on the cutaneous collagen/elastin fibers and carotenoids: negative effects can be reduced by application of sunscreen. J Biophotonics 7:735-743. doi:10.1002/jbio.201300171

Datta R, Alfonso-Garciá A, Cinco R, Gratton E. 2015. Fluorescence lifetime imaging of endogenous biomarker of oxidative stress. Sci Rep 5:1-10. doi:10.1038/srep09848

Digman MA, Caiolfa VR, Zamai M, Gratton E. 2008. The phasor approach to fluorescence lifetime imaging analysis. Biophys J 94:L14-6. doi:10.1529/biophysj.107.120154

Dong B, Almassalha LM, Stypula-Cyrus Y, Urban BE, Chandler JE, Nguyen T-Q, Sun C, Zhang HF, Backman V. 2016. Superresolution intrinsic fluorescence imaging of chromatin utilizing native, unmodified nucleic acids for contrast. Proc Natl Acad Sci 113:9716-9721. doi:10.1073/pnas.1602202113

Dupré-Crochet S, Erard M, Nüße O. 2013. ROS production in phagocytes: why, when, and where? J Leukoc Biol 94:657-670. doi:10.1189/jlb.1012544

Duque GA, Descoteaux A. 2014. Macrophage cytokines: Involvement in immunity and infectious diseases. Front Immunol 5:1-12. doi:10.3389/fimmu.2014.00491

Elhelu MA. 1983. The role of macrophages in immunology. J Natl Med Assoc 75:314-7.

Estandarte AK, Botchway S, Lynch C, Yusuf M, Robinson I. 2016. The use of DAPI fluorescence 
lifetime imaging for investigating chromatin condensation in human chromosomes. Sci Rep 6:1-12. doi:10.1038/srep31417

Ferrer MF, Thomas P, Ortiz AOL, Errasti AE, Charo N, Romanowski V, Gorgojo J, Rodriguez ME, Silva EAC, Gómez RM. 2019. Junin virus triggers macrophage activation and modulates polarization according to viral strain pathogenicity. Front Immunol 10:1-12. doi:10.3389/fimmu.2019.02499

Fitzpatrick TB. 1988. The Validity and Practicality of Sun-Reactive Skin Types I Through VI. Arch Dermatol 124:869-871.

Forman HJ, Torres M. 2001. Redox signaling in macrophages. Mol Aspects Med 22:189-216. doi:10.1016/S0098-2997(01)00010-3

Fukui S, Iwamoto N, Takatani A, Igawa T, Shimizu T, Umeda M, Nishino A, Horai Y, Hirai Y, Koga T, Kawashiri SY, Tamai M, Ichinose K, Nakamura H, Origuchi T, Masuyama R, Kosai K, Yanagihara K, Kawakami A. 2018. M1 and M2 Monocytes in rheumatoid arthritis: A contribution of imbalance of M1/M2 monocytes to osteoclastogenesis. Front Immunol 8:110. doi:10.3389/fimmu.2017.01958

Furukawa S, Moriyama M, Miyake K, Nakashima H, Tanaka A, Maehara T, Iizuka-Koga M, Tsuboi H, Hayashida JN, Ishiguro N, Yamauchi M, Sumida T, Nakamura S. 2017. Interleukin33 produced by $\mathrm{M} 2$ macrophages and other immune cells contributes to Th2 immune reaction of IgG4-related disease. Sci Rep 7:1-10. doi:10.1038/srep42413

Geissmann F, Manz M, Jung S, Sieweke M, Merad M, Ley K. 2010. Development of monocytes, macrophages and dendritic cells. Science (80-) 327:565-661. doi:10.1126/science.1178331.Development

Gordon S, Taylor PR. 2005. Monocyte and macrophage heterogeneity. Nat Rev Immunol 5:953964. doi:10.1038/nri1733

Heaster TM, Heaton AR, Sondel PM, Skala MC. 2021. Intravital Metabolic Autofluorescence Imaging Captures Macrophage Heterogeneity Across Normal and Cancerous Tissue. Front Bioeng Biotechnol 9:1-10. doi:10.3389/fbioe.2021.644648

Kang K, Hammerberg C, Meunier L, Cooper KD. 1994. CD11b+ macrophages that infiltrate human epidermis after in vivo ultraviolet exposure potently produce IL-10 and represent the major secretory source of epidermal IL-10 protein. J Immunol 153:5256-5264.

König K. 2008. Clinical multiphoton tomography. $J$ Biophotonics 1:13-23. doi:10.1002/jbio.200710022

Koo S jie, Garg NJ. 2019. Metabolic programming of macrophage functions and pathogens control. Redox Biol 24:101198. doi:10.1016/j.redox.2019.101198

Kröger M, Scheffel J, Nikolaev V V, Shirshin EA, Siebenhaar F, Schleusener J, Lademann J, Maurer M, Darvin ME. 2020. In vivo non-invasive staining-free visualization of dermal mast cells in healthy, allergy and mastocytosis humans using two-photon fluorescence lifetime imaging. Sci Rep 10:14930. doi:10.1038/s41598-020-71901-2

Lakner PH, Monaghan MG, Möller Y, Olayioye MA, Schenke-Layland K. 2017. Applying phasor approach analysis of multiphoton FLIM measurements to probe the metabolic activity of threedimensional in vitro cell culture models. Sci Rep 7. doi:10.1038/srep42730

Li Y, Liu TM. 2018. Discovering macrophage functions using in Vivo optical imaging techniques. Front Immunol 9:1-20. doi:10.3389/fimmu.2018.00502

Malissen B, Tamoutounour S, Henri S. 2014. The origins and functions of dendritic cells and macrophages in the skin. Nat Rev Immunol 14:417-428. doi:10.1038/nri3683

Malmgaard L, Melchjorsen J, Bowie AG, Mogensen SC, Paludan SR. 2004. Viral Activation of Macrophages through TLR-Dependent and -Independent Pathways. J Immunol 173:68906898. doi:10.4049/jimmunol.173.11.6890

May RC, Machesky LM. 2001. Phagocytosis and the actin cytoskeleton. J Cell Sci 114:1061-1077. McWhorter FY, Wang T, Nguyen P, Chung T, Liu WF. 2013. Modulation of macrophage 
phenotype by cell shape. Proc Natl Acad Sci $U$ S A 110:17253-17258. doi:10.1073/pnas.1308887110

Melton DW, McManus LM, Gelfond JAL, Shireman PK. 2015. Temporal phenotypic features distinguish polarized macrophages in vitro. Autoimmunity 48:161-176. doi:10.3109/08916934.2015.1027816

Mendoza-Coronel E, Ortega E. 2017. Macrophage polarization modulates FcyR- and CD13mediated phagocytosis and reactive oxygen species production, independently of receptor membrane expression. Front Immunol 8. doi:10.3389/fimmu.2017.00303

Morhenn VB, Lemperle G, Gallo RL. 2002. Phagocytosis of different particulate dermal filler substances by human macrophages and skin cells. Dermatologic Surg 28:484-490. doi:10.1046/j.1524-4725.2002.01273.x

Mosser DM, Edwards JP. 2008. Exploring the full spectrum of macrophage activation. Nat Rev Immunol 8:958-969. doi:10.1038/nri2448

Murray PJ, Allen JE, Biswas SK, Fisher EA, Gilroy DW, Goerdt S, Gordon S, Hamilton JA, Ivashkiv LB, Lawrence T, Locati M, Mantovani A, Martinez FO, Mege JL, Mosser DM, Natoli G, Saeij JP, Schultze JL, Shirey KA, Sica A, Suttles J, Udalova I, vanGinderachter JA, Vogel SN, Wynn TA. 2014. Macrophage Activation and Polarization: Nomenclature and Experimental Guidelines. Immunity 41:14-20. doi:10.1016/j.immuni.2014.06.008

Myers JT, Tsang AW, Swanson JA. 2003. Localized Reactive Oxygen and Nitrogen Intermediates Inhibit Escape of Listeria monocytogenes from Vacuoles in Activated Macrophages. $J$ Immunol 171:5447-5453. doi:10.4049/jimmunol.171.10.5447

Nielsen MC, Andersen MN, Møller HJ. 2020. Monocyte isolation techniques significantly impact the phenotype of both isolated monocytes and derived macrophages in vitro. Immunology 159:63-74. doi:10.1111/imm.13125

Njoroge JM, Mitchell LB, Centola M, Kastner D, Raffeld M, Miller JL. 2001. Characterization of viable autofluorescent macrophages among cultured peripheral blood mononuclear cells. Cytometry 44:38-44. doi:10.1002/1097-0320(20010501)44:1<38::AIDCYTO1080>3.0.CO;2-T

Pergola C, Schubert K, Pace S, Ziereisen J, Nikels F, Scherer O, Hüttel S, Zahler S, Vollmar AM, Weinigel C, Rummler S, Müller R, Raasch M, Mosig A, Koeberle A, Werz O. 2017. Modulation of actin dynamics as potential macrophage subtype-targeting anti-tumour strategy. Sci Rep 7:1-12. doi:10.1038/srep41434

Ploeger DT, Hosper NA, Schipper M, Koerts JA, De Rond S, Bank RA. 2013. Cell plasticity in wound healing: Paracrine factors of M1/ M2 polarized macrophages influence the phenotypical state of dermal fibroblasts. Cell Commun Signal 11:1-17. doi:10.1186/1478811X-11-29

Porcheray F, Viaud S, Rimaniol AC, Léone C, Samah B, Dereuddre-Bosquet N, Dormont D, Gras G. 2005. Macrophage activation switching: An asset for the resolution of inflammation. Clin Exp Immunol 142:481-489. doi:10.1111/j.1365-2249.2005.02934.x

Ramond E, Jamet A, Coureuil M, Charbit A. 2019. Pivotal role of mitochondria in macrophage response to bacterial pathogens. Front Immunol 10:1-11. doi:10.3389/fimmu.2019.02461

Remmerie A, Scott CL. 2018. Macrophages and lipid metabolism. Cell Immunol 330:27-42. doi:10.1016/j.cellimm.2018.01.020

Rendra E, Riabov V, Mossel DM, Sevastyanova T, Harmsen MC, Kzhyshkowska J. 2019. Reactive oxygen species (ROS) in macrophage activation and function in diabetes. Immunobiology 224:242-253. doi:10.1016/j.imbio.2018.11.010

Ryter A. 1985. Relationship between ultrastructure and specific functions of macrophages. Comp Immunol Microbiol Infect Dis 8:119-133. doi:10.1016/0147-9571(85)90039-6

Schmid MA, Harris E. 2014. Monocyte Recruitment to the Dermis and Differentiation to Dendritic Cells Increases the Targets for Dengue Virus Replication. PLoS Pathog 10. 
doi:10.1371/journal.ppat.1004541

Shirshin EA, Gurfinkel YI, Priezzhev A V., Fadeev V V., Lademann J, Darvin ME. 2017. Twophoton autofluorescence lifetime imaging of human skin papillary dermis in vivo: Assessment of blood capillaries and structural proteins localization. Sci Rep 7:1171. doi:10.1038/s41598017-01238-w

Shirshin EA, Yakimov BP, Darvin ME, Omelyanenko NP, Rodionov SA, Gurfinkel YI, Lademann J, Fadeev V V., Priezzhev A V. 2019. Label-Free Multiphoton Microscopy: The Origin of Fluorophores and Capabilities for Analyzing Biochemical Processes. Biochem 84:69-88. doi:10.1134/s0006297919140050

Sica A, Mantovani A. 2012. Macrophage plasticity and polarization: in vivo veritas. J Clin Invest 122:787-795. doi:10.1172/JCI59643DS1

Swindle EJ, Hunt JA, Coleman JW. 2002. A Comparison of Reactive Oxygen Species Generation by Rat Peritoneal Macrophages and Mast Cells Using the Highly Sensitive Real-Time Chemiluminescent Probe Pholasin: Inhibition of Antigen-Induced Mast Cell Degranulation by Macrophage-Derived Hydrogen Pero. $J$ Immunol 169:5866-5873. doi:10.4049/jimmunol.169.10.5866

Szulczewski JM, Inman DR, Entenberg D, Ponik SM, Aguirre-Ghiso J, Castracane J, Condeelis J, Eliceiri KW, Keely PJ. 2016. In Vivo Visualization of Stromal Macrophages via label-free FLIM-based metabolite imaging. Sci Rep 6:1-9. doi:10.1038/srep25086

Theret M, Mounier R, Rossi F. 2019. The origins and non-canonical functions of macrophages in development and regeneration. Dev 146:1-14. doi:10.1242/dev.156000

Viola A, Munari F, Sánchez-Rodríguez R, Scolaro T, Castegna A. 2019. The metabolic signature of macrophage responses. Front Immunol 10:1-16. doi:10.3389/fimmu.2019.01462

Vogel DYS, Heijnen PDAM, Breur M, de Vries HE, Tool ATJ, Amor S, Dijkstra CD. 2014. Macrophages migrate in an activation-dependent manner to chemokines involved in neuroinflammation. J Neuroinflammation 11:1-11. doi:10.1186/1742-2094-11-23

Walsh AJ, Mueller KP, Tweed K, Jones I, Walsh CM, Piscopo NJ, Niemi NM, Pagliarini DJ, Saha K, Skala MC. 2021. Classification of T-cell activation via autofluorescence lifetime imaging. Nat Biomed Eng 5:77-88. doi:10.1038/s41551-020-0592-z

Weber-Matthiesen K, Sterry W. 1990. Organization of the monocyte/macrophage system of normal human skin. J Invest Dermatol 95:83-89. doi:10.1111/1523-1747.ep12874002

Xu Q, Choksi S, Qu J, Jang J, Choe M, Banfi B, Engelhardt JF, Liu ZG. 2016. NADPH oxidases are essential for macrophage differentiation. $J$ Biol Chem 291:20030-20041. doi:10.1074/jbc.M116.731216

Yakimov BP, Gogoleva MA, Semenov AN, Rodionov SA, Novoselova M V., Gayer A V., Kovalev A V., Bernakevich AI, Fadeev V V., Armaganov AG, Drachev VP, Gorin DA, Darvin ME, Shcheslavskiy VI, Budylin GS, Priezzhev A V., Shirshin EA. 2019. Label-free characterization of white blood cells using fluorescence lifetime imaging and flow-cytometry: molecular heterogeneity and erythrophagocytosis. Biomed Opt Express 10:4220. doi:10.1364/boe.10.004220

Yanez DA, Lacher RK, Vidyarthi A, Colegio OR. 2017. The role of macrophages in skin homeostasis. Pflugers Arch Eur J Physiol 469:455-463. doi:10.1007/s00424-017-1953-7

Yang L, Shami A. 2020. On hyperparameter optimization of machine learning algorithms: Theory and practice. Neurocomputing 415:295-316. doi:https://doi.org/10.1016/j.neucom.2020.07.061

Yuan R, Li S, Geng H, Wang X, Guan Q, Li X, Ren C, Yuan X. 2017. Reversing the polarization of tumor-associated macrophages inhibits tumor metastasis. Int Immunopharmacol 49:30-37. doi:10.1016/j.intimp.2017.05.014

Zhang XM, Lund H, Mia S, Parsa R, Harris RA. 2014. Adoptive transfer of cytokine-induced immunomodulatory adult microglia attenuates experimental autoimmune encephalomyelitis 
in DBA/1 mice. Glia 62:804-817. doi:10.1002/glia.22643

\section{Acknowledgments}

General: We thank Evelin Hagen, Niklas Mahnke and Loris Busch from Charité Universitätsmedizin Berlin for their excellent technical support. We thank David Satzinger for the schematic illustration of MФs.

Funding: Foundation for Skin Physiology of the Donor Association for German Science and Humanities (MK, JS, MCM, JL, MED)

Russian Science Foundation №19-75-10077 «Photonic and Quantum technologies. Digital medicine» (ES).

Author contributions: M.E.D., J.L. and M.M. planned and designed the study. M.K., M.E.D., J.Sche., J.Schl., E.A.S., M.C.M. J.L. and M.M. conceived the experiments. M.K. and M.E.D. performed the experiments. M.K., J.Sche., J.Schl., E.A.S. and M.E.D. analyzed the data. M.E.D., M.K. and M.M. wrote the main manuscript text. All authors reviewed the manuscript.

\section{Competing interests:}

The authors declare no competing interests in relation to this work, or other interests that might be perceived to influence the results and/or discussion reported in this paper.

Marcus Maurer is or recently was a speaker and/or advisor for and/or has received research funding from Allakos, Amgen, Aralez, ArgenX, AstraZeneca, BioCryst, Celldex, Centogene, CSL Behring, FAES, Genentech, GIInnovation, Gilead, Innate Pharma, Kalvista, Kyowa Kirin, Leo Pharma, Lilly, Menarini, Moxie, Novartis, Pharming, Pharvaris, Roche, Sanofi/Regeneron, Shire/Takeda, Third HarmonicBio, UCB, and Uriach. 